\title{
Multi-track, Multi-layer Dendrite Growth and Solid Phase Transformation Analysis during Additive Manufacturing of H13 Tool Steel Using a Combined Hybrid Cellular Automata/Phase Field and Solid- state Phase Prediction Models
}

Neil Bailey

Purdue University

Yung C. Shin ( $\nabla$ shin@ecn.purdue.edu )

Purdue University

\section{Research Article}

Keywords: microstructure, additive manufacturing, $\mathrm{H} 13$, predictive modeling, solid-state phase transformation

Posted Date: December 6th, 2021

DOI: https://doi.org/10.21203/rs.3.rs-1132364/v1

License: (1) This work is licensed under a Creative Commons Attribution 4.0 International License. Read Full License

Version of Record: A version of this preprint was published at The International Journal of Advanced Manufacturing Technology on February 18th, 2022. See the published version at https://doi.org/10.1007/s00170-022-08901-1. 


\title{
Multi-track, Multi-layer Dendrite Growth and Solid Phase Transformation Analysis during Additive Manufacturing of H13 Tool Steel Using a Combined Hybrid Cellular Automata/Phase Field and Solid-state Phase Prediction Models
}

\author{
Neil S. Bailey and Yung C. Shin ${ }^{1}$ \\ Center for Laser-based Manufacturing \\ Purdue University, West Lafayette Indiana, 47907, USA
}

\begin{abstract}
Using an efficient hybrid Cellular Automata/Phase Field (CA-PF) dendrite growth modeling in combination with a solid phase transformation model, microstructure evolution and solid-phase transformation were predicted during laser direct deposition (LDD) of $\mathrm{H} 13$ tool steel powder across multiple tracks and layers. Temperature and surface geometry data were provided by a comprehensive physics-based laser deposition model. The computational efficiency of the CAPF model allows for simulating domains large enough to capture dendrite growth across an entire molten pool and into neighboring LDD tracks. The microstructure of the target track is strongly affected by heat from neighboring tracks including re-melting and re-solidification, and martensite tempering. Dendrite size and growth direction across the entire fusion zone, as well as predicted hardness values, are found to be in good agreement with experimental results.
\end{abstract}

Keywords: microstructure; additive manufacturing, H13, predictive modeling; solid-state phase transformation

\footnotetext{
${ }^{1}$ Corresponding author: shin@purdue.edu, 1-765-494-9775 (ph), 1-765-494-0539 (fax)
} 


\section{Introduction}

\subsection{Laser direct deposition}

Laser direct deposition (LDD) of metals is a multi-track, multi-layer additive manufacturing (AM) process where fine metal powders are blown into the same focal point as the laser, either coaxially [1] or off-axis [2]. The laser directs enough energy at the focal point to create a molten pool, thereby melting the incoming powder that is directed at the molten pool. As the molten pool and directed powder stream travel together at the laser travel speed, the back of the molten pool experiences very rapid solidification while the addition of powder builds up the surface of the part.

AISI H13 tool steel is extensively used in toolings for hot work and cold work. Its high hardness, strength, and resistance to thermal fatigue cracking at an elevated temperature make it ideal for use in high-pressure die casting tooling, hot forging dies, extrusion dies, and plastic injection molding dies [3]. Traditionally, H13 tooling is cut from blocks with a long lead time to obtain material; but in recent years, AM has facilitated the creation of conformal cooling where coolant passages are printed within the tool to allow superior heat removal to previously inaccessible areas [4], [5]. Additionally, complex die surfaces with loops, deep trenches, and metal savers are increasingly difficult and costly to subtractively manufacture, while AM tooling requires only finishing machining and/or electrical discharge machining (EDM).

While AM provides many advantages such as the creation of complex shapes and no required tooling, it also carries many disadvantages, aside from the cost, which are less well understood. With subtractive manufacturing, the material properties of a machined part are mostly carried over from the stock material. Since the material properties of stock materials are well 
understood and well regulated, the material properties after subtractive manufacturing are well controlled. However, with laser or e-beam AM processes for metals, the AM part undergoes local melting and solidification throughout the building process, resulting in the unknown and widely varying microstructure.

The traditional choice for developing material properties of AM processes is experimentation and measurement. However, the huge numbers and ranges of experimental variables that affect material properties (not to mention the numbers of processes, materials, and AM machines available) make this approach very time consuming and expensive.

The alternative choice, physics-based numerical simulation, is a more desirable way. The foundation of predicting material properties is an accurate prediction of the resultant microstructure and phase transformation after an AM process is performed, all of which require accurate temperature calculation [6]-[9]. Microstructure prediction involves simulating dendrite growth [10]-[12]. A quick literature search will reveal that the two most popular numerical methods for simulating dendrite growth are the Cellular Automata (CA) and Phase Field (PF) methods.

Cellular Automata models specialize in the simulation of micro-scale dendrite growth as well as meso-scale grain growth. The strength of these models lies in their computational efficiency, but their accuracy is completely dependent on the accurate determination of growth velocity of the solid/liquid interface. In a typical example [13], the growth velocity of the interface is calculated based on the undercooling as predicted by an analytical model such as the Kurz-Giovanola-Trivedi (KGT) model [14], which assumes equilibrium solidification conditions and a parabolic dendrite tip shape. This restricts the model's accuracy to that of the 
analytical model, which ought to be applied only to steady-state situations, limiting the simulation to qualitative prediction. As another example, a more recent model implicitly calculates the growth velocity at the solid/liquid interface by solving the transport equations for both solid and liquid phases while holding a solute concentration boundary condition at the interface [15]-[19], but is only quantitatively accurate for domains of low Péclet number [20]$[22]$.

Early CA models used to predict dendrite growth were limited to pure materials and binary alloys. Several attempts have been made to expand these approaches to more complex material systems such as multi-component and/or multi-phase alloys [21], [23]-[25], but most of them have made simplifying assumptions, which limit their applicability. Tan and Shin [26] developed a 3D CA model to predict grain growth during laser melting processes of austenitic stainless steel. More recently, Gu et al. [27] presented a 3D CA model with a quantitative prediction of dendrite growth in ternary alloys applicable at low cooling rates and near steadystate growth conditions, but it is not applicable at cooling rates associated with laser melting processes [28].

The Phase Field method is a more elegant solution with a much higher computational cost. It is established on a set of thermodynamically based partial differential equations, with a diffuse solid/liquid interface defined by the parameter $\phi$ [29]-[33]. This modeling method has been widely used to study growth kinetics for different multicomponent alloys on very small scales due to the high computational cost [34]-[40]. Kim et al. [41] presented the most influential multi-component PF model (expanded from their two-phase binary PF model [42]). Because the PF equations are thermodynamically based, the CALPHAD method has widely been used, in conjunction with the PF equations, to calculate the Gibbs energy of the system. This 
makes PF easily applicable to ternary alloys [34], [35], [37], [43], [44] and higher-order systems [45], [46], and realistic multi-phase microstructure patterns have been obtained.

The major disadvantage of the PF method is the extremely high computational cost. Compared to the CA method, the PF method requires a very fine mesh to characterize the diffuse interface, greatly limiting the domain size of PF models. Adaptive mesh refinement methods have only slightly alleviated the computational cost [47]-[49].

A novel CA-PF model [50] that combines the strengths of the CA and PF methods was proposed by the authors' group to accurately predict the solidification and dendrite growth of multi-component alloys on a scale large enough to capture an entire molten pool. This model has been used for the quantitative prediction of dendrite growth and micro-segregation during solidification of multi-component alloys over areas large enough to visualize molten pools in laser cladding [7] and laser welding of austenitic stainless steel [26]. In this paper, the model has been expanded to include simulation of multi-track and multi-layer additive processes, including re-melting and re-solidification of previously deposited tracks. To the author's best knowledge, this is the first time the solidification and dendrite growth of an entire molten pool of a ternary alloy undergoing fast transient cooling has been modeled with the influence of multiple tracks and layers typical of AM processes.

In addition to melting and solidification processes, solid-phase transformation can also have a strong effect on the material properties of AM parts and cannot be neglected. Hypoeutectic steels can undergo dramatic solid phase transformation during rapid heating and cooling caused by multiple heating cycles from neighboring tracks. A solid-phase transformation 
model [9], [51] was also merged with the CA-PF model to calculate the tempering effects of the heating and cooling cycles inherent to laser-based additive processes.

The CA-PF model and the solid phase transformation model discussed in this paper get their needed temperature and surface geometry field data from a validated, comprehensive multiphysics thermal model $[1,52]$ that was developed in-house. This model considers multi-phase heat transfer from conduction, convection, and radiation, as well as free-surface tracking of the molten pool surface via the level-set method [53]. The details of this thermal model are skipped for brevity, as it is well described in Ref. [1]. The major contribution of this work is to elucidate the microstructure and phase evolution involving re-melting, re-solidification, and solid-phase transformation for an entire cross-section of an LDD track during a multi-track and multi-layer LDD process using the integrated computationally efficient CA-PF and solid phase transformation models in combination joined with temperature and geometry data from a comprehensive thermal model is used.

\section{Numerical models}

\subsection{CA-PF model}

All details of the CA-PF model have been presented by Tan et al. [50], but an adequate explanation is given here for the purposes and scope of this paper. A flowchart, shown in Figure 1, helps describe the working of the CAPF model. Temperature data from the thermal model is provided to the CAPF model (described in detail in Section 3.1). The CA portion of the model uses the temperature data to calculate the solute diffusion in the CA domain and determine the initial shape of the solid/liquid interface. Then, for each interface cell in the CA domain, the CA 
model sends and receives data to and from the PF model, which calculates the growth kinetics along the solid/liquid interface.

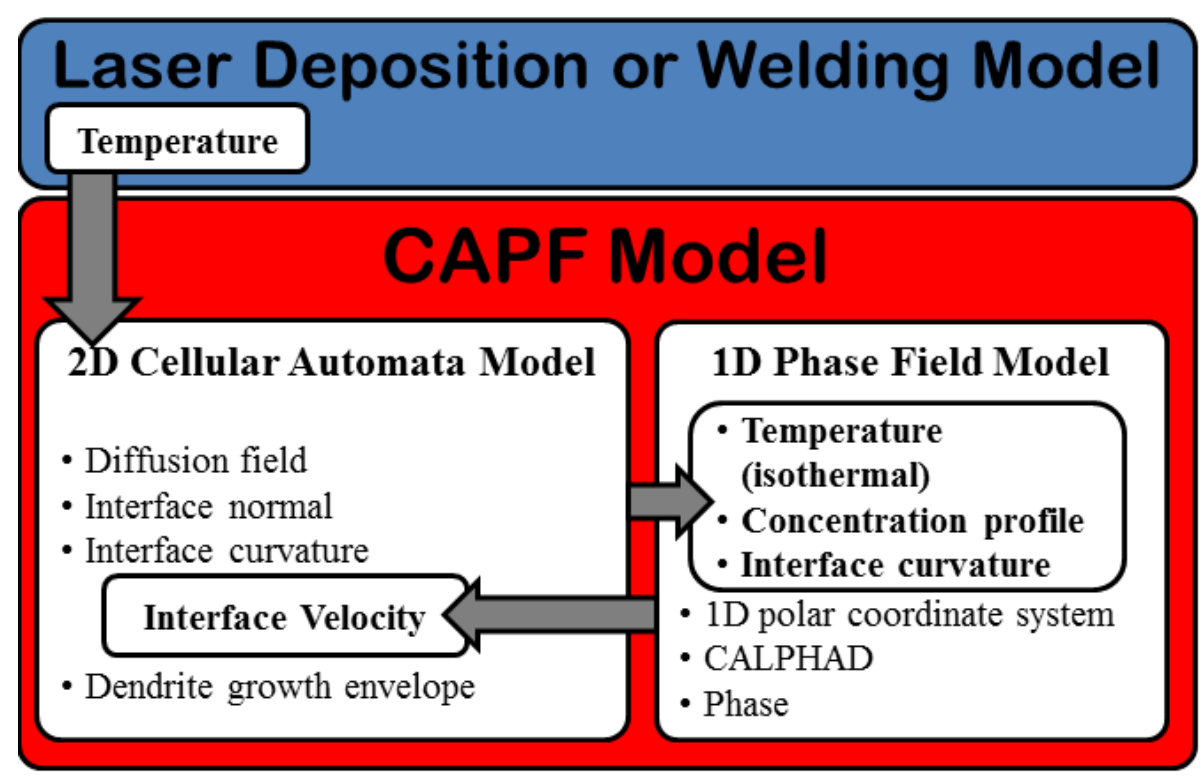

Figure 1: Flowchart for the CAPF model.

\subsubsection{Cellular automata}

The discretized domain of the CA model consists of regular square cells where each cell can be assigned one of three state variables: liquid, interface, or solid. Other important values needed for calculating the growth kinetics of each cell include solute concentration $C$ for each solute (two solutes in a ternary alloy), temperature $T$, a vector $\beta$ normal to the solid-liquid interface, curvature value $K$, and crystallographic orientation $\theta$.

Dendrite growth occurs when increasing numbers of cells change their states from liquid to interface and then to solid. The state change of each cell is determined by the decentered 
square algorithm [54] such that a nucleus grows by a square envelope whose corner aligns with the crystallographic orientation $\theta$, as shown in Figure 2.

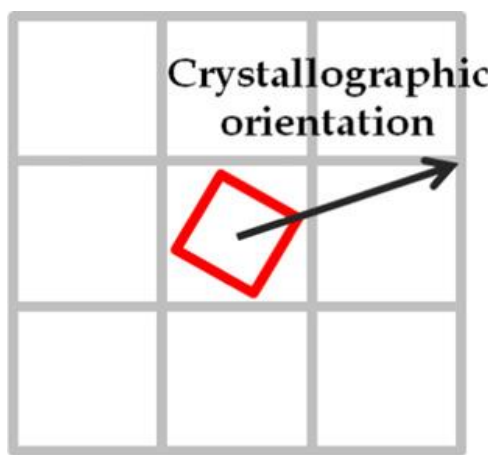

(a)

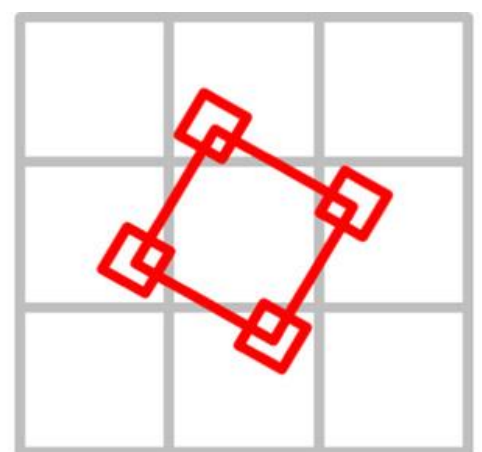

(b)

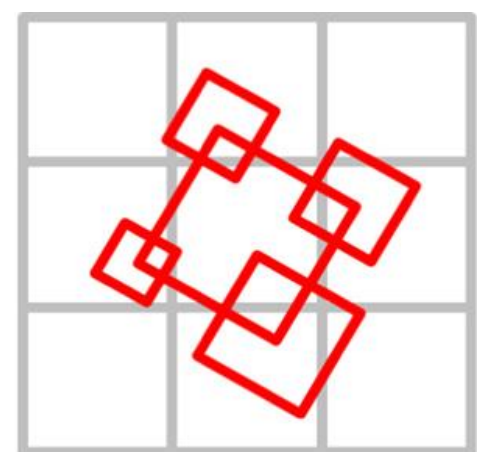

(c)

Figure 2: Visual explanation of the decentered square algorithm (from Ref. [50])

The growth of the envelope is governed by Eq. (1),

$$
L=\sum_{t} V\left(t_{i}\right) \Delta t
$$

where $L$ is half the length of envelope diagonal, $t$ is the time duration of the interface state of the cell, $V\left(t_{i}\right)$ is the velocity of the solid-liquid interface at time $t_{i}$, and $\Delta t$ is the time step length. As the envelope expands during growth, it will contact neighboring cells. If the "contacted" cell is liquid, it will be reassigned as an interface cell. The crystallographic orientation of the "parent" cell will then be passed on to the new interface cells, and the new "daughter" cells' envelopes will center at the corners of the parent cell's envelope (Figure 2b). The child cells will then expand with their own velocities that may be different from that of the parent envelope (Figure 2c) and will assign other liquid cells as interface cells as they grow sufficiently large. The solid fraction, $f_{S}$, of each cell is governed by Eq. (2), 


$$
f_{S}=\frac{L}{\Delta x(|\sin \theta|+\cos \theta)}
$$

where $\Delta x$ denotes the mesh size of the CA model. Once $f_{S}$ reaches 1 , the interface cell is considered solid and is no longer included in the calculations of interface cells.

Two alloying components must be considered in a ternary system. During solidification at the interface, a certain amount of each solute is rejected into the liquid while each solute also diffuses throughout the liquid. This solute diffusion and rejection of each alloying component is governed by

$$
\frac{\partial C_{e, i}}{\partial t}=\nabla \cdot\left(D_{e, i} \nabla C_{e, i}\right)+\frac{\partial f_{S}}{\partial t}\left(C_{L, i}^{I}-C_{S, i}^{I}\right) \quad(i=1,2)
$$

where $D_{e, i}$ and $C_{e, i}$ are the equivalent diffusion and composition coefficients for liquid, interface, and solid cells, and $C_{L, i}^{I}$ and $C_{S, i}^{I}$ are the liquid/solid concentrations at the interface

The normal vector $\beta$ at the solid-liquid interface, as shown in Figure 3, and the curvature, $K$, are needed to calculate the growth kinetics of each interface cell; $\beta$ for an interface cell is calculated by using Raghavan's algorithm [55]. As shown in Figure 3, a circle is drawn inside a $7 \times 7$ cell area centered on the cell of interest. Point $C$, the mass center of the solid area within the circle, is then calculated based on a weighted average of the solid fractions of the cells. The vector between point $\mathrm{C}$ and point $\mathrm{A}$ is the normal vector $\beta$ of the interface at cell $\mathrm{A}$. 


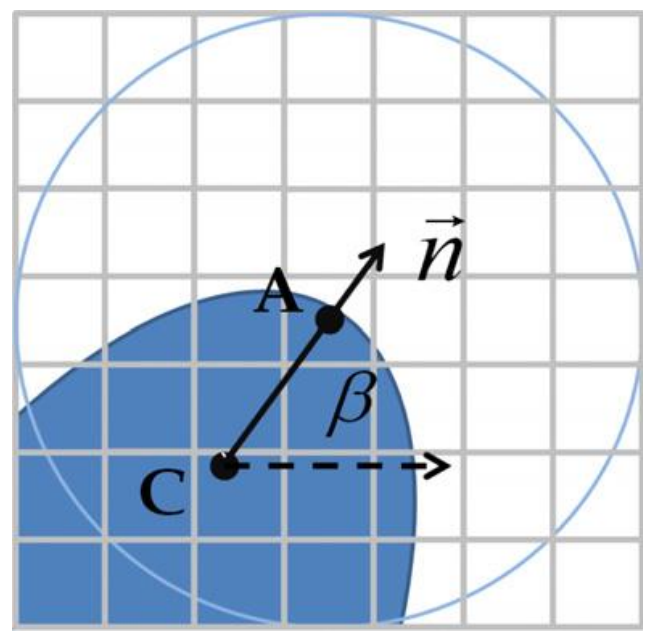

Figure 3: Illustration depicting Raghavan's algorithm [55] to determine the interface normal using a $7 \times 7$ grid.

The calculation of the curvature $K$ is based on the work of Martorano et al. [56]. First, as illustrated in Figure 4, a line segment is used to approximate the curve of the interface in each interface cell inside a $3 \times 3$ cell area centered on the cell of interest. A polynomial is then calculated based on the midpoints of each line segment with the normal vector $\beta$ as the polynomial's vertical axis, $\mathrm{y}^{\prime}$, and the origin, point $\mathrm{O}$, at the midpoint of the cell of interest. The curvature can then be calculated from the polynomial.

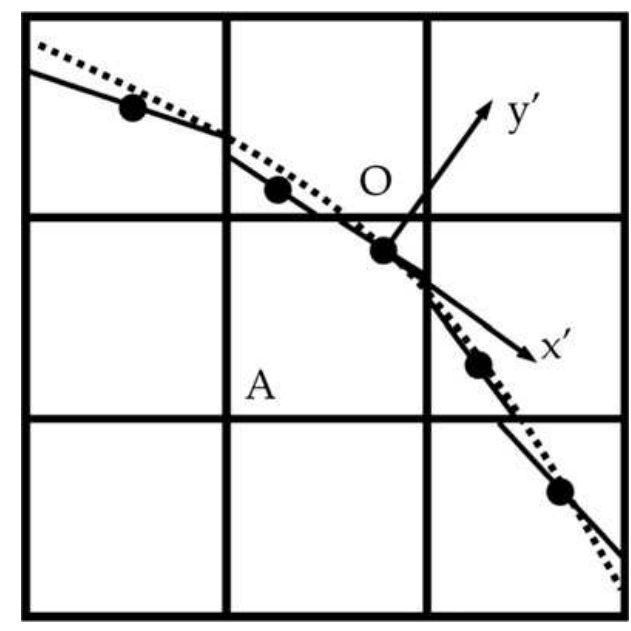

Figure 4: Determination of interface curvature (from [50]) 
After the temperature and concentration field are calculated on the CA mesh and the interface normal vectors and curvatures are known, the growth kinetic values of interface velocity $V$ and the interface concentrations $C_{L, i}^{I}$ and $C_{S, i}^{I}$ are calculated from the PF model.

\subsubsection{Phase field model}

The sole purpose of the phase field model is to provide the cellular automata model with accurate local growth kinetics along the solid/liquid interface based on local solidification conditions. It is assumed that the local interface growth at a given interface cell can be approximated as 1D growth as long as the direction is always normal to the interface. Therefore, a 1D phase field model should be sufficient for calculating the local growth kinetics along the solid/liquid interface.

The PF model may be expressed by Eq. (4) and Eq. (5) [37], [42], [43], [57], [58].

$$
\begin{gathered}
\frac{1}{M_{\phi}} \frac{\partial \phi}{\partial t}=\varepsilon^{2} \nabla^{2} \phi-\frac{\partial f}{\partial \phi} \\
\frac{\partial C_{i}}{\partial t}=\nabla \cdot \sum_{j}^{n}\left(D_{i j} \nabla C_{j}\right)+\nabla \cdot \sum_{j}^{n}\left(M_{i j} \frac{\partial^{2} f}{\partial C_{j} \partial \phi} \nabla \phi\right)
\end{gathered}
$$

Here, the order parameter of the phase field is represented by $\phi, M_{\phi}$ is the phase field mobility, $\varepsilon$ is the gradient energy coefficient, and $f$ represents the free energy density. The concentration of each component $i$ of the alloy is $C_{i}$, while $D_{i j}$ and $M_{i j}$ are the $(i, j)$ th components of the material diffusion and mobility matrices, respectively.

If this system is solved in 1D, it would simulate the solidification of a planar interface. Yet locally, at the interface, the curvature of a dendrite strongly affects the velocity of the 
solidification interface. For example, an interface with a positive curvature, such as the tip of a dendrite, will solidify much faster than a planar interface since the rejected solute can diffuse to the sides of the dendrite tip. On the other hand, an interface with a negative curvature such as the area near the base of a dendrite arm will solidify much slower than a planar interface since the ejected solute cannot diffuse away and is trapped by an inward-curving interface. A 1D planar PF model would underestimate the growth near the tip of a dendrite and overestimate the growth near the root of the dendrites.

Therefore, the 1D PF model (Eq. (4) and (5)) has been reformulated into a polar coordinate system with radius $r=1 / K$.

$$
\begin{gathered}
\frac{1}{M_{\phi}} \frac{\partial \phi}{\partial t}=\frac{1}{r} \frac{\partial}{\partial r}\left(\varepsilon^{2} r \frac{\partial \phi}{\partial r}\right)-\frac{\partial f}{\partial \phi} \\
\frac{\partial C_{i}}{\partial t}=\frac{1}{r} \frac{\partial}{\partial r}\left(r \sum_{j}^{n}\left(D_{i j} \frac{\partial C_{i}}{\partial r}\right)\right)+\frac{1}{r} \frac{\partial}{\partial r}\left(r \sum_{j}^{n}\left(M_{i j} \frac{\partial^{2} f}{\partial C_{j} \partial \phi}\right) !\right.
\end{gathered}
$$

The effect of interface curvature is incorporated into the model through this 1D polar formulation. By using this formulation, a unique circular shape for each interface cell, depending on the local shape of the dendrite, can be assumed to calculate the growth kinetics of the solid phase. The solidification velocity of the interface is then dependent on the local curvature and the concentration gradient(s) of the solute(s). A detailed description of all relevant PF equations required in the CA-PF model is presented by Tan et al. [50]. For multicomponent alloys, more than one phase may form upon solidification. To determine which phases will form, the PF model is linked to a CALPHAD database which calculates Gibb's energy of the system.

\subsubsection{CA-PF Combination}


The PF model needs the interface curvature, concentration distribution for each solute in the alloy, and the temperature to replicate the local solidification conditions in order to calculate the growth kinetics for a CA interface cell. For diffusion-controlled dendrite growth, the concentration distribution is the strongest factor and can be accurately described with a 1D concentration profile in the PF model. A number of points along the interface cell's normal vector are interpolated from the CA model's concentration fields onto the PF model's 1D concentration profile, as shown in Figure 5. For example, the solute concentrations of point 1 are interpolated from the values of cells B, C, D and E. A typical cell size for the CA model's mesh is $0.5 \mu \mathrm{m}$, while a typical cell size in the 1D PF model is $0.25 \mu \mathrm{m}$. The $1 \mathrm{D}$ concentration profile along the vector is described by Eq. (8).

$$
C_{i}(x)=C_{\infty, i}+\left(C_{L, i}^{I}-C_{\infty, i}\right) \exp \left(-A_{i} x\right)
$$

Here, $C_{L, i}^{I}$ is the concentration at the interface, $C_{\infty, i}$ is the concentration far from the interface, $A_{i}$ is a variable that defines the exponential strength of the concentration profile, and $x$ is the distance from the interface into the liquid in the normal direction. The concentration value at the interface, $C_{L, i}^{I}$, is known from the last CA time step, the concentration value far from the interface, $C_{\infty, i}$, is found at distance into the melt where far enough away from the interface that the value does not change significantly, and $A_{i}$ is determined from the concentration values of the $1 \mathrm{D}$ profile. The interface concentrations, $C_{L, i}^{I}$, and $A_{i}$ are then used by the PF model, along with the local temperature and curvature, to determine local growth velocity and equilibrium concentrations at the interface. 


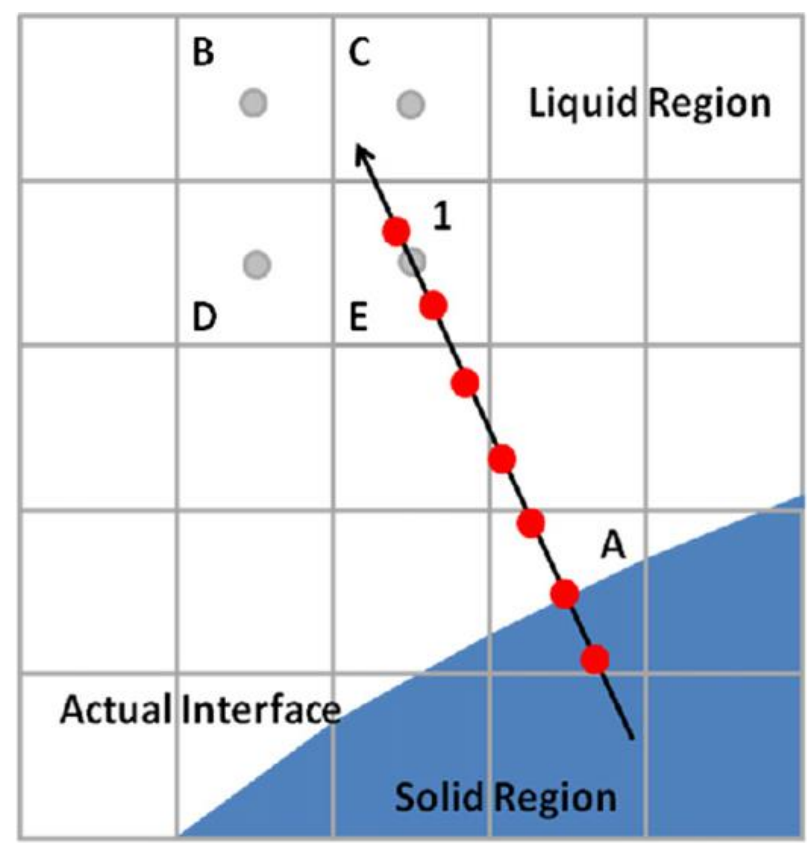

Figure 5: 1D concentration profile along Cell A's normal vector is interpolated from the CA model to the PF model (adapted from [50])

To correctly set up the PF model, the mid-point of the PF interface $(\phi=0.5)$ must be positioned at $r=1 / K$ in the polar coordinate domain. The temperature used in the PF model is assumed to be isothermal at temperature $T$ of the interface cell. The isothermal assumption is valid because the variation in temperature along the normal vector is much smaller than the variation in concentration(s) across the distance the interface advances during one CA time step.

With the values of temperature and curvature and the concentration profile provided by the CA model, the PF model can precisely predict the progression of the solidification interface. This velocity of the PF solidification interface is the interface velocity, $V\left(t_{i}\right)$, needed in the CA model (Eq. (1)) and is the main purpose of the PF model. Several time steps are required for the PF model to reach convergence from the initial concentration profile as given by the CA model. Once convergence has been reached, the interface velocity of the PF model is given to the CA 
model, along with values of the solid and liquid interface concentrations $C_{L, i}^{I}$ and $C_{S, i}^{I}$ taken from the PF model's converged 1D concentration profile. The CA model can then determine the overall growth of the dendrite via the de-centered square algorithm Eq. (2), and the macroscale diffusion within the liquid via Eq. (3). With the CA model and the PF model working together, the dendrite growth can be predicted over a large area with accurate growth kinetics of multicomponent alloys and with the efficiency of a CA model and the precision of a PF model.

\subsection{Solid-phase transformation model}

Both microstructure characteristics (grain size, secondary dendrite arm spacing (SDAS), etc.) and solid phase have strong influences on the material properties of a part. Although solid phase transformation kinetics is a characteristic of microstructure, it is not trivial to predict solid phase from dendrite growth simulation data. Therefore, the CA-PF model has been expanded to include solid-phase transformation prediction capabilities. A full description of the solid phase transformation model is provided by Bailey et al. [9], but an adequate description is presented here.

Three temperature-dependent processes are included in the model: heating, cooling, and tempering. To simulate the heating cycle, a 2D kinetic model was developed by Skvarenina and Shin [59] based on Ashby and Easterling's work [60]. This model was expanded to include the tempering effect by Lakhkar et al. [61]. Bailey et al. [51] further expanded the model to 3D and included cooling effects.

Rapid heating and cooling are defining characteristics of laser-based manufacturing processes. The heating cycle is explained graphically in Figure 6. As temperature increases past the eutectoid temperature $\left(727^{\circ} \mathrm{C}\right)$ depicted by point b in Figure 6, all high-carbon pearlite 
regions will transform into austenite. The ferrite regions are slower to transform to austenite because of a lack of carbon. As temperature further increases, carbon from the newly formed austenite regions will diffuse into the low-carbon ferrite regions, transforming them into austenite. As temperature increases, carbon diffusion also increases. If the temperature increases beyond the austenization temperature $\left(850^{\circ} \mathrm{C}\right.$ for $\mathrm{H} 13$ steel $)$, all remaining ferrite will transform into austenite, as depicted by point c in Figure 6. For slow heating cycles, carbon diffusion cannot be neglected when modeling the solid-state phase transformation. However, the rapid heating of laser-based processes makes modeling the carbon diffusion irrelevant. In the present model, all material with a temperature above the austenization temperature is assumed to have transformed to $100 \%$ austenite. For temperatures between the eutectic and austenization temperatures, the lever rule defined by Callister and Rethwisch [62] is used to determine the fraction between austenite and ferrite.

In this model, the rapid cooling cycle uses the Sheil's additive rule and follows Kang and Im's implementation of the Johnson-Mehl-Avrami-Kolmogorov (JMAK) model [63] and the implementation of Woodard et al. [64] of the Koistinen-Marburger (KM) equation. The details of this model are presented by Bailey et al. [9], [51]. 


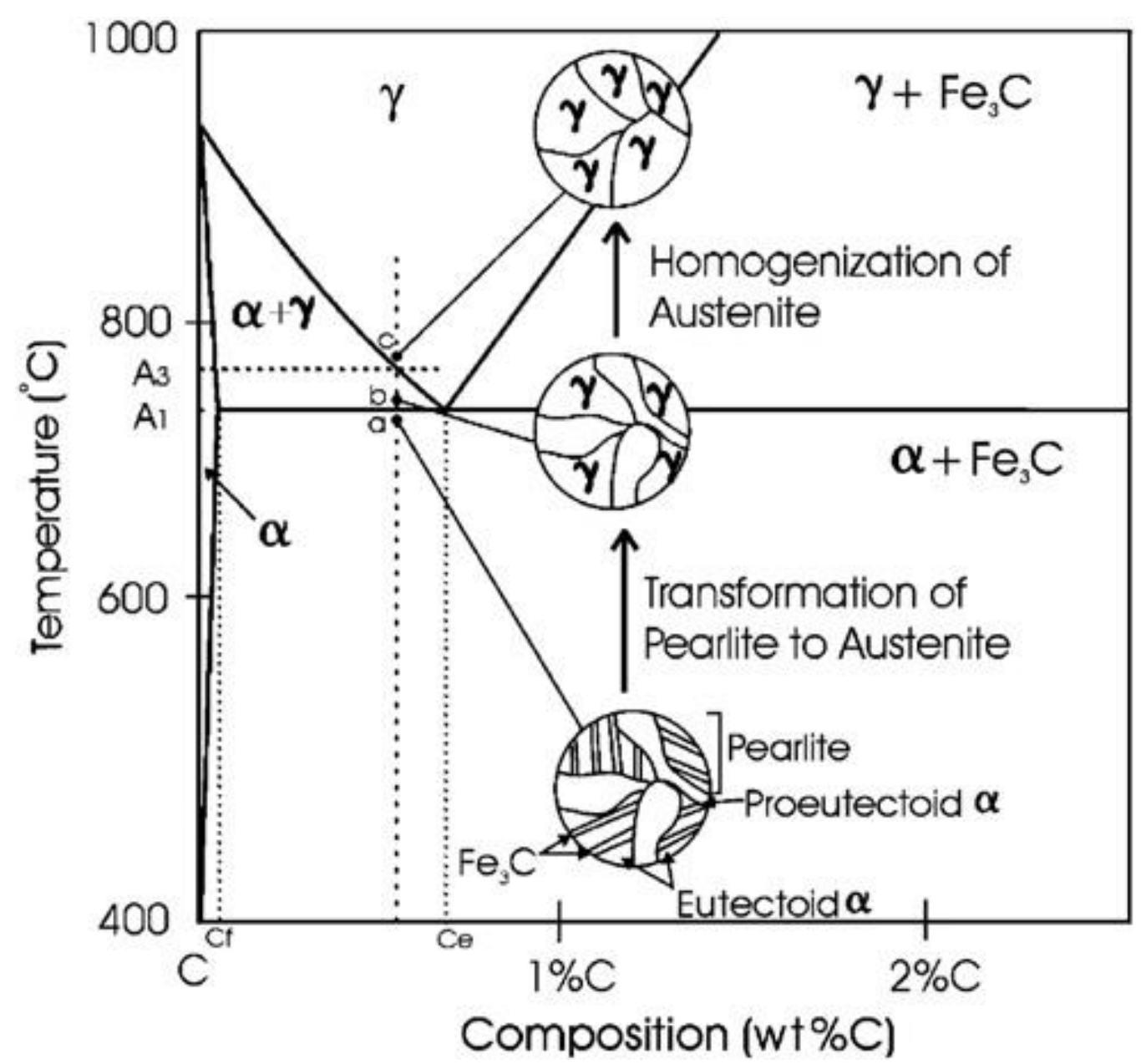

Figure 6: Microstructural changes in hypo-eutectoid steel during heating (adopted from [65]).

The multi-track and multi-layer nature of LDD requires the use of a tempering model [61]. Below the eutectoid temperature, pearlite and ferrite phases are stable while martensite can be tempered at temperatures between $100^{\circ} \mathrm{C}$ and the eutectoid temperature. During LDD, the peak temperature during a single track reaches far above the eutectoid temperature, resulting in rapid cooling and a track that is mostly martensite. However, as the laser deposits additional tracks next to and above this track, the heat from these tracks will cause the martensite to temper significantly. This tempering effect must be considered when modeling the solid-state phase transformation of multi-track and multi-layer LDD. 
In the tempering model, any martensite phase fraction higher than zero in a given cell will experience tempering if the temperature rises above $100^{\circ} \mathrm{C}$ while remaining below the eutectoid temperature $727^{\circ} \mathrm{C}$. Between $100^{\circ} \mathrm{C}$ and $250^{\circ} \mathrm{C}$, a certain fraction of the martensite phase fraction will transform to $\varepsilon$-carbide and ferrite while cementite and ferrite are formed between $250^{\circ} \mathrm{C}$ and $727^{\circ} \mathrm{C}$. The fraction of martensite, $f_{m}$, that is transformed into these tempered phases is calculated based on the JMA equation:

$$
f_{m}=1-e^{-\beta n}
$$

Here, $n$ is a constant set at 0.109 [61]. For non-isothermal processes, the $\beta$ term is governed by the differential equation,

$$
\frac{d \beta}{d t}=k+\frac{Q}{R T^{2}} \beta \frac{d T}{d t}
$$

where the activation energy, $Q=1.97 \times 10^{5}$, and $k=5.11 \times 10^{9}$ is a constant.

The fractions of $\varepsilon$-carbide $\left(f_{\varepsilon}\right)$ and ferrite $\left(f_{\alpha}\right)$ that form between $100^{\circ} \mathrm{C}$ and $250^{\circ} \mathrm{C}$ from the phase fraction of tempered martensite $\left(f_{m}\right)$ is given by

$$
f_{\varepsilon}=\frac{f_{m} C_{H 13}-C_{\alpha}}{C_{\varepsilon}-C_{\alpha}}=f_{m}-f_{\alpha}
$$

where the carbon concentration of $\mathrm{H} 13, C_{H 13}=0.4 \%$, and the carbon concentrations of $\varepsilon$ carbide and ferrite are $C_{\varepsilon}=8.55 \%$ and $C_{\alpha}=8.22 \%$, respectively. Similarly, cementite $\left(f_{c}\right)$ and ferrite $\left(f_{\alpha}\right)$ form between $250^{\circ} \mathrm{C}$ and $727^{\circ} \mathrm{C}$, according to Eq. (12)

$$
f_{c}=\frac{f_{m} C_{H 13}-C_{\alpha}}{C_{c}-C_{\alpha}}=f_{m}-f_{\alpha}
$$

with a carbon concentration of cementite, $C_{c}=6.7 \%$. 
Once all the phase fractions are calculated, the hardness field can be calculated by the weighted average of the hardness of each phase according to Eq. (13).

$$
H=\sum f_{i} H_{i}
$$

While the solidification as predicted by the CA-PF model occurs very rapidly during cooling near the solidus and liquidus temperatures, the solid phase transformation occurs over a much longer temperature span and time including heating, cooling, and multi-track and -layer tempering. Although these two pieces of the model are solved simultaneously and use the same domain and mesh size, they have a separate time scale and time steps.

\subsection{Material}

To predict solidification microstructure and dendrite growth with the CA-PF model during additive manufacturing of $\mathrm{H} 13$ tool steel, this complex tool steel alloy is first approximated as a ternary alloy. The composition of H13 tool steel is given in Table 1. The top three elements are iron, chromium, and molybdenum. Therefore, the ternary system to be implemented into a CALPHAD subroutine is the Fe-Cr-Mo system, as studied by Andersson and Lange [66] with appropriate Gibb's energy coefficients for equilibrium states for liquid and the iron Image result for face-centered cubic (FCC) crystal structure (austenite) solid phase. For simulations in this paper, the initial concentrations of chromium and molybdenum were set at 5.0 and $1.5 \mathrm{wt} . \%$, respectively. 
Table 1: Composition of H13 tool steel [67] in wt.\%

\begin{tabular}{cc}
\hline Element & Composition \\
$\mathrm{C}$ & $0.32-0.45$ \\
$\mathrm{Cr}$ & $4.75-5.5$ \\
$\mathrm{Mn}$ & $0.2-0.5$ \\
$\mathrm{Mo}$ & $1.1-1.75$ \\
$\mathrm{Ph}$ & $0.03 \mathrm{max}$ \\
$\mathrm{Si}$ & $0.8-1.2$ \\
$\mathrm{~S}$ & $0.03 \max$ \\
$\mathrm{V}$ & $0.8-1.2$ \\
$\mathrm{Fe}$ & balance \\
\hline
\end{tabular}

\section{Simulation and results}

\subsection{AM thermo-fluid dynamics modeling results}

The temperature data used by the CA-PF model in this work was calculated using a validated, comprehensive multi-physics laser direct deposition (LDD) thermal model [1], [52]. For the situation presented in this study, tracks are built in parallel with the operating parameters listed in Table 2 as presented in [9]. Each track is offset $0.300 \mathrm{~mm}$ from the previous track. The next layer is then deposited $0.300 \mathrm{~mm}$ above the surface of the previous layer. For multi-track deposition, it was found that the geometry of the third track accurately represents the geometry of each additional track [9]. Therefore, the quasi-steady state temperature field and geometry predicted by the LDD model of a third track simulation are provided to the CA-PF model. The temperature field and track geometry, as predicted by the LDD model, are shown in Figure 7. 
Table 2: Optimal operating parameters for multi-layer LDD of H13 tool steel [9].

\begin{tabular}{lrl}
\hline Laser power & 350 & $\mathrm{~W}$ \\
Laser travel speed & 14.8 & $\mathrm{~mm} / \mathrm{s}$ \\
Powder flow rate & 8.5 & $\mathrm{~g} / \mathrm{min}$ \\
Track spacing & 0.3 & $\mathrm{~mm}$ \\
\hline
\end{tabular}

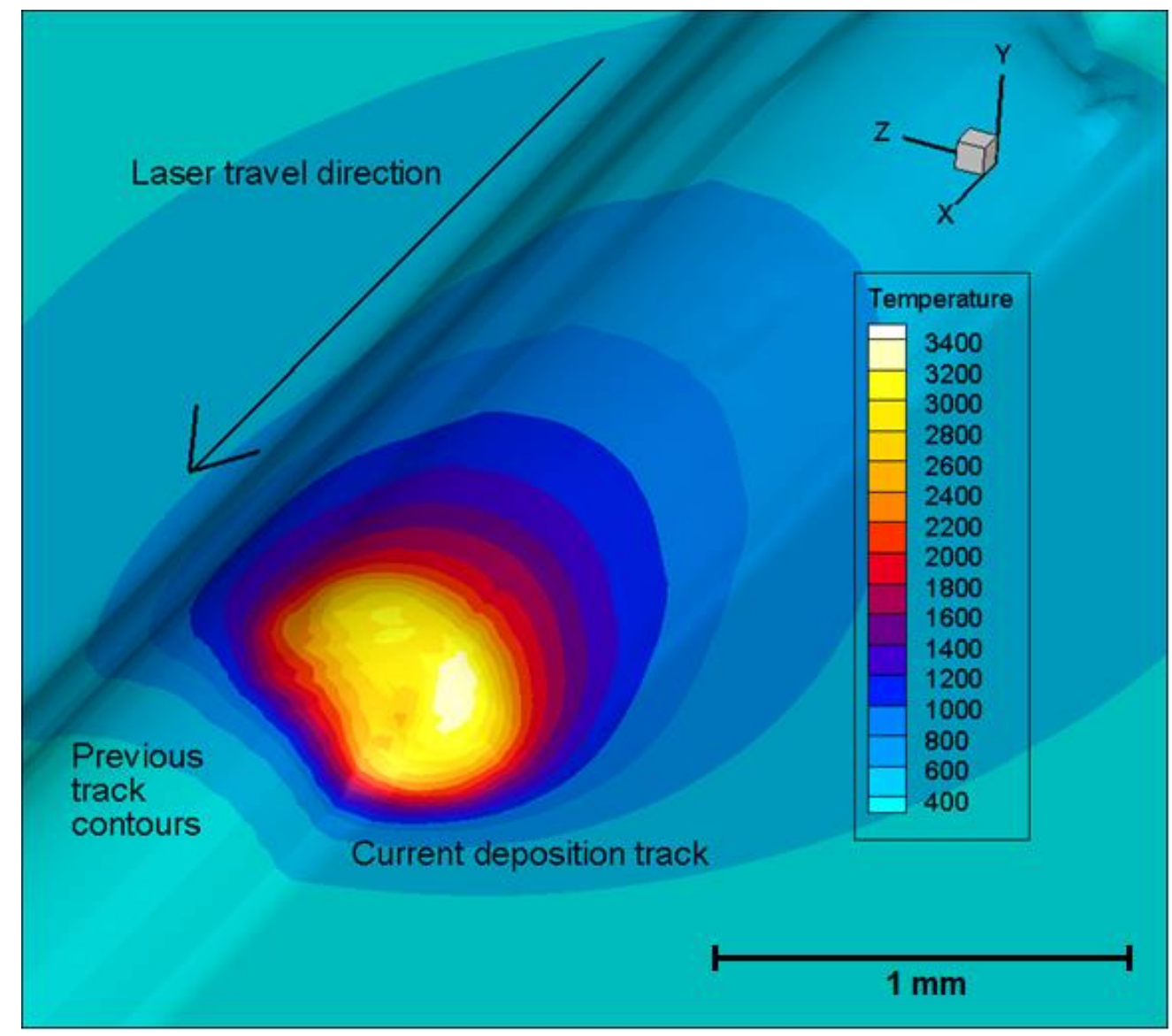

Figure 7: Multi-track direct deposition simulation results from which the temperature (Kelvin) data for the CA-PF simulation is taken.

The 3D temperature field and track geometry of both the molten pool and the solidified track are used as input parameters for the 2D CA-PF model. The term track geometry indicates the overall shape and surface profile of the track. This is predicted for both the molten pool 
(before the metal solidifies) and the solidified track geometry. The molten pool geometry will be transient due to rigorous fluid flow within the molten pool. The thermal model predicts this transient geometry and this data is used in the CA-PF model. The temperature and geometry data are read into the CA-PF model at the beginning of the CA-PF analysis. The 2D CA-PF analysis domain is $430 \mu \mathrm{m}$ high and $300 \mu \mathrm{m}$ wide and the initial location of the analysis plane is at the heart of the molten pool (the bright region in Figure 7) where the analysis plane has the maximum amount of liquid before solidification begins. As time progresses, the 3D temperature field is brought forward (relative to the 2D CA-PF analysis plane) in the laser travel direction and at the laser travel speed. At each time step of the CA-PF simulation, the temperature for the CA-PF simulation is interpolated from the LDD model's 3D temperature field at the current relative position of the 2D CA-PF analysis plane. As the CA-PF 2D domain moves through the molten pool toward the solid region, solidification begins and dendrites will start to grow within the CA-PF analysis plane, according to the thermodynamic conditions of the domain. A track's simulation is complete when all of the 2D CA-PF domain is solidified. To simulate multi-track and multi-layer dendrite growth, the CA-PF region is shifted laterally by the track spacing $(0.300$ $\mathrm{mm}$ in this paper) for each track and each layer, and then the next track begins again with the $2 \mathrm{D}$ CA-PF analysis plane in the heart of the molten pool. Areas of the second track that were previously solid and now have a temperature higher than the melt temperature are reset as liquid and are subsequently re-solidified during the second track's simulation.

In this paper, four tracks were simulated: two on the first layer and two on the second layer. The locations of each of these simulations are depicted in Figure 8. The microstructure is first predicted by the CA-PF model in the red box labeled "CA-PF initial simulation domain location." After the dendrite growth simulation of the first track is complete, this predicted 
microstructure is then used as the initial microstructure for the second simulation at the location indicated in Figure 8. The small black boxes indicate the locations of the lower left-hand corners of each simulation location. Simulations 3 and 4 then use the previous simulations' predicted microstructure as their initial microstructures, resulting in the final microstructure predicted in the green region labeled "CA-PF final simulation domain location."

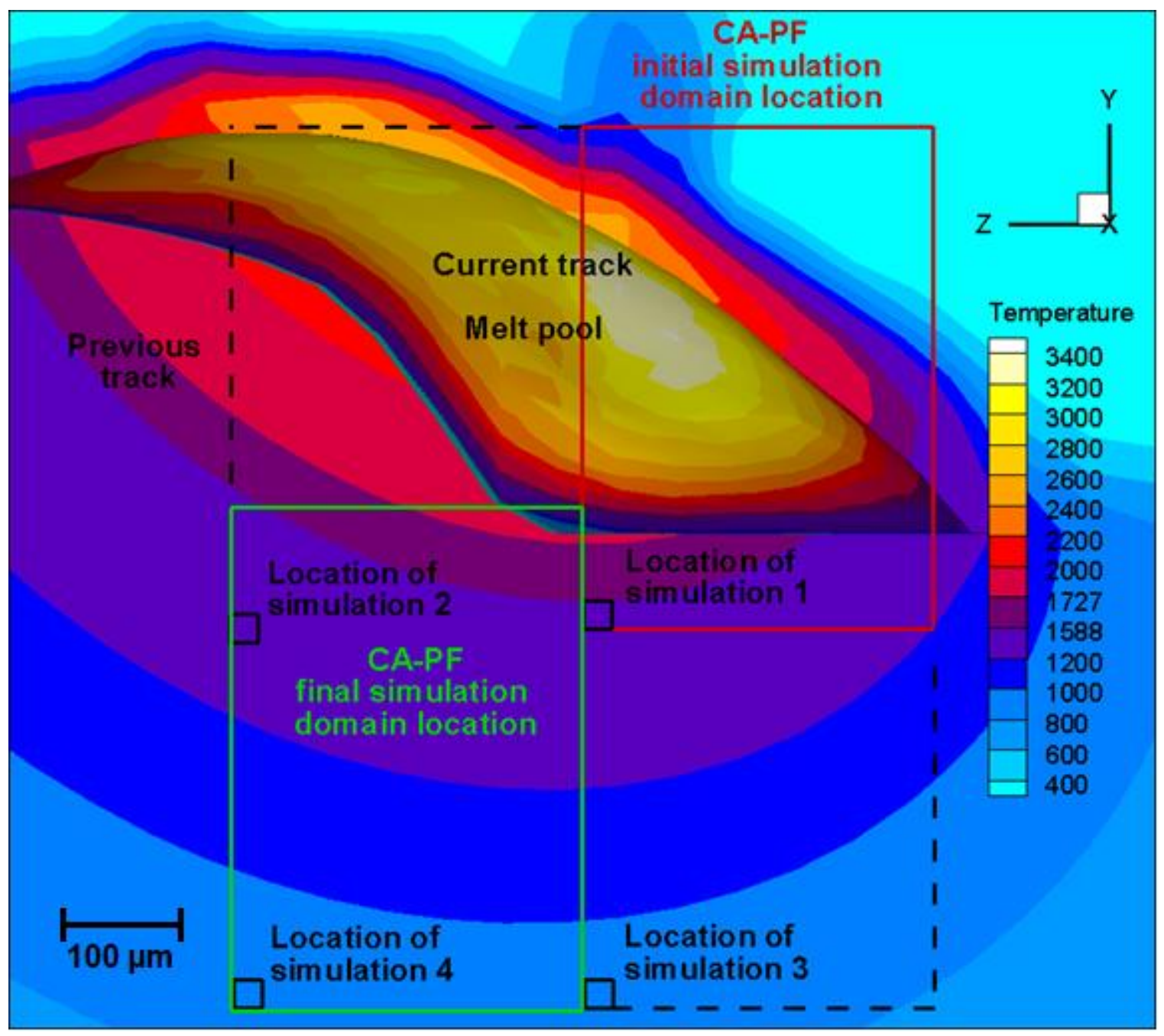

Figure 8: Head-on view of direct deposition track with temperature distribution in Kelvin. Laser travel is in the $\mathrm{X}$ direction (out of the page). 
The background temperature field shown in Figure 8 (a head-on view of the LDD simulation) represents the $2 \mathrm{D}$ temperature as interpolated from the 3D temperature data from the LDD model at a certain point in simulation time. The area in the top half of Figure 8 labeled "Current track Melt pool" represents the temperature and geometry of the molten pool. The order of the four simulations, as they appear in Figure 8, is not the order in which each track is deposited, but the order of microstructure evolution. In other words, the microstructure in simulation is formed first, gets affected by the deposition in the adjacent track as in simultation 2 . Therefore, the microstructure in simulation 2 is modeled using the microstructure formed in simulation 1 and the temperature history in simulation 2 . Therefore, the microstructure of the multi-track, multilayer deposition will go through the evolution shown in simulation 1, 2, 3 and 4. Obviously, a track in the position of simulation 4 as shown in Figure 8 would be the first of the four tracks to be deposited, but has gone through the evolution of simulation 1, 2 and 3 before the final microstructure is formed. This is the only track that is being considered in the microstructure prediction simulations as noted by the text "CA-PF final simulation domain location" in Figure 8. The temperature field of each neighboring track will strongly affect the final microstructure predicted at this location. Therefore, the four locations noted in Figure 8 depict the positions of the temperature field relative to the final simulation domain location as deposition occurs for each neighboring track. Each of the four simulations required about 20 hours of computation on Intel Xeon CPU E5-2660 v3 with 20 cores at $2.6 \mathrm{GHz}$. This does not include the computational cost of the thermal model results which can be found in reference [68].

\subsection{Single track results}

Results for the first track, Simulation 1, are shown in Figure 9 through Figure 11. The coordinate system of the CA-PF model, as shown in Figure 9, is not the same as the coordinate 
system of the thermal model shown in Figure 7 and Figure 8. However, the x/y plane of the CAPF model is always parallel to the $y / z$ plane of the thermal model. The first track simulation begins at the heart of the molten pool with the temperature profile shown in Figure 9. The values of some of the isotherms have been adjusted to show the boundary of the molten pool and the location of the mushy zone.
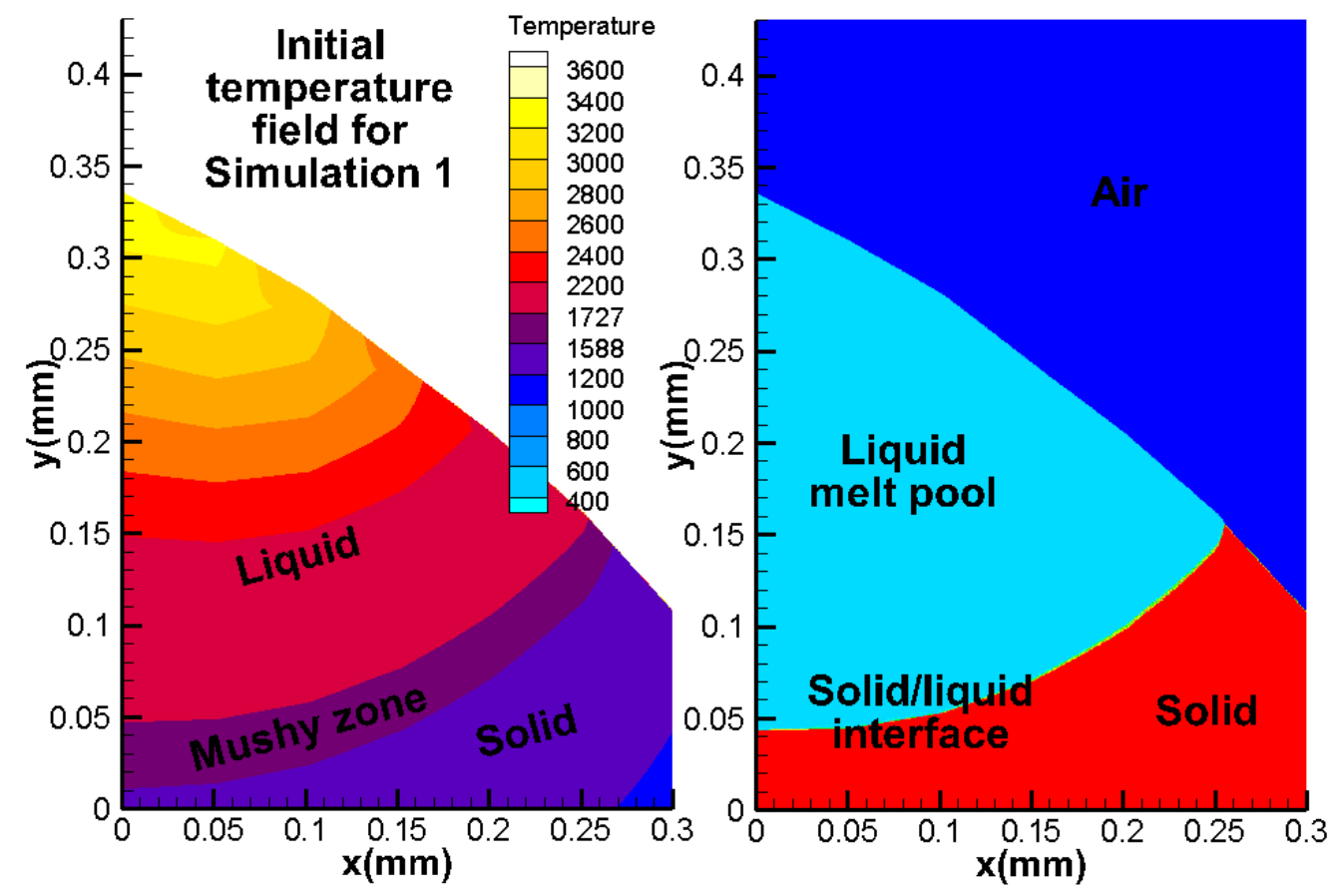

Figure 9: Initial temperature field (in Kelvin) and phases before dendrite growth begins for the first track (Simulation 1).

As the temperature begins to drop, randomly oriented seeds are randomly placed at the back of the molten pool and grains will begin to grow in the direction of the temperature gradient, as shown in Figure 10. The first solidified phase here is austenite with a face-centered cubic structure. The dendrites with crystallographic orientations that are closely aligned with the temperature gradient will grow more quickly, blocking the dendrites with less favorable 
orientations. The competitive growth is clearly seen in the zoomed-in image of Figure 10, as well as the detailed microstructure predicted by the CA-PF model. Once the temperature cools sufficiently, the melt in the entire 2D CA-PF domain will completely solidify, as shown in Figure 11.

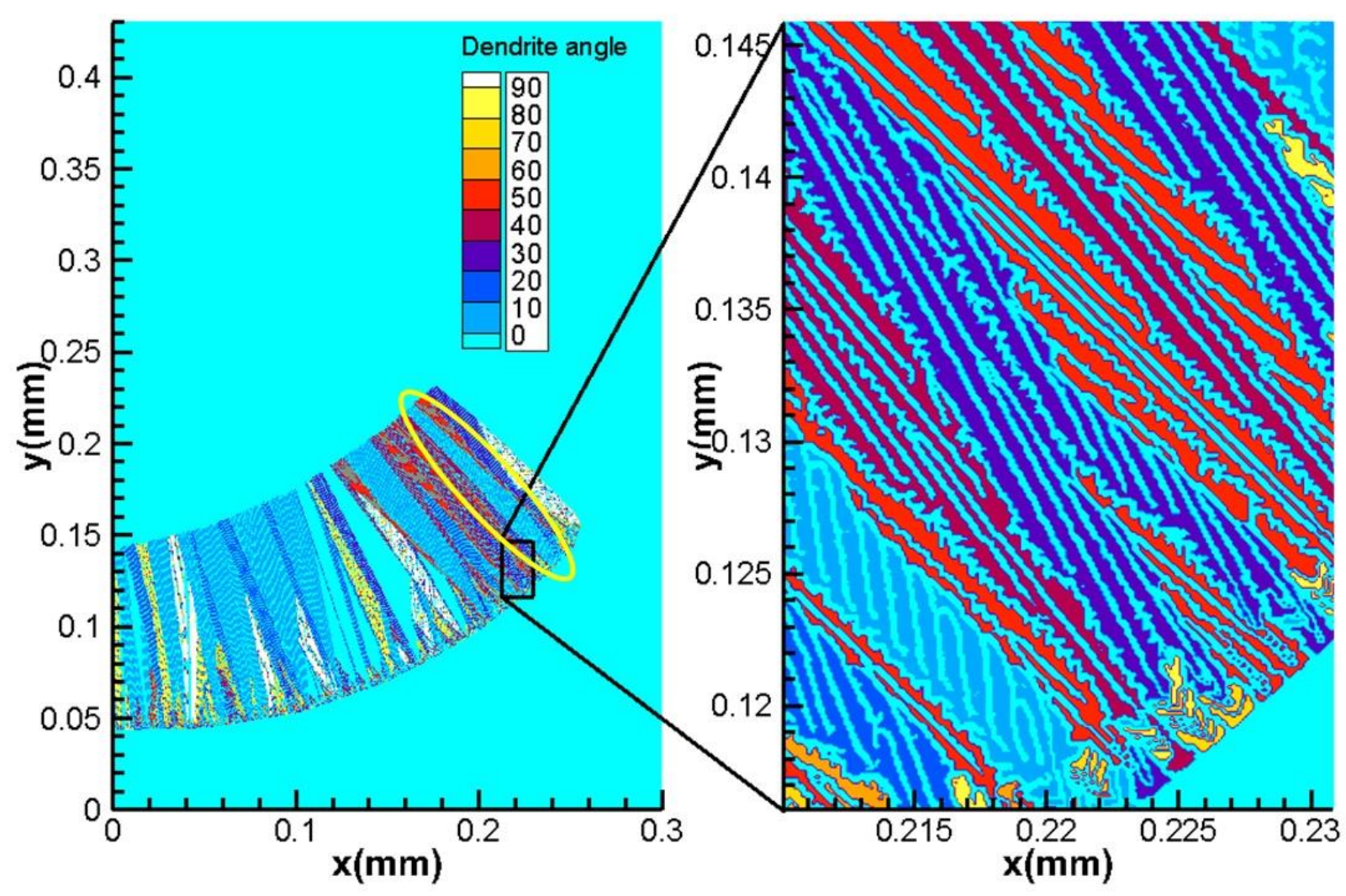

Figure 10: The microstructure during solidification of the first track (Simulation 1) (left). A zoomed-in view near the bottom of the molten pool showing individual dendrites, secondary dendrite growth, and competitive growth (right).

In any directional solidification process, grains with a favorable orientation will have an advantage over less favorable orientations, but this is only an advantage — not an absolute outcome. The competitive growth phenomenon will reliably produce large-scale trends, as seen in Figure 10. Near the left side of the left figure are shown a majority of orientations at or near $0^{\circ}$ 
or $90^{\circ}$ growing in the y-direction, while grains on the right side of the left figure are growing diagonally and are primarily $30^{\circ}$ to $60^{\circ}$ orientations. The overall trend is obvious, but some grains may beat the odds and successfully grow in unfavorable directions. In Figure 10, a grain with an orientation close to $0^{\circ}$, indicated by a yellow oval, grows in unfavorable conditions where the temperature gradient is close to $45^{\circ}$. However, in Figure 11 it is shown that the same grain is eventually blocked by grains with orientations close to $45^{\circ}$.

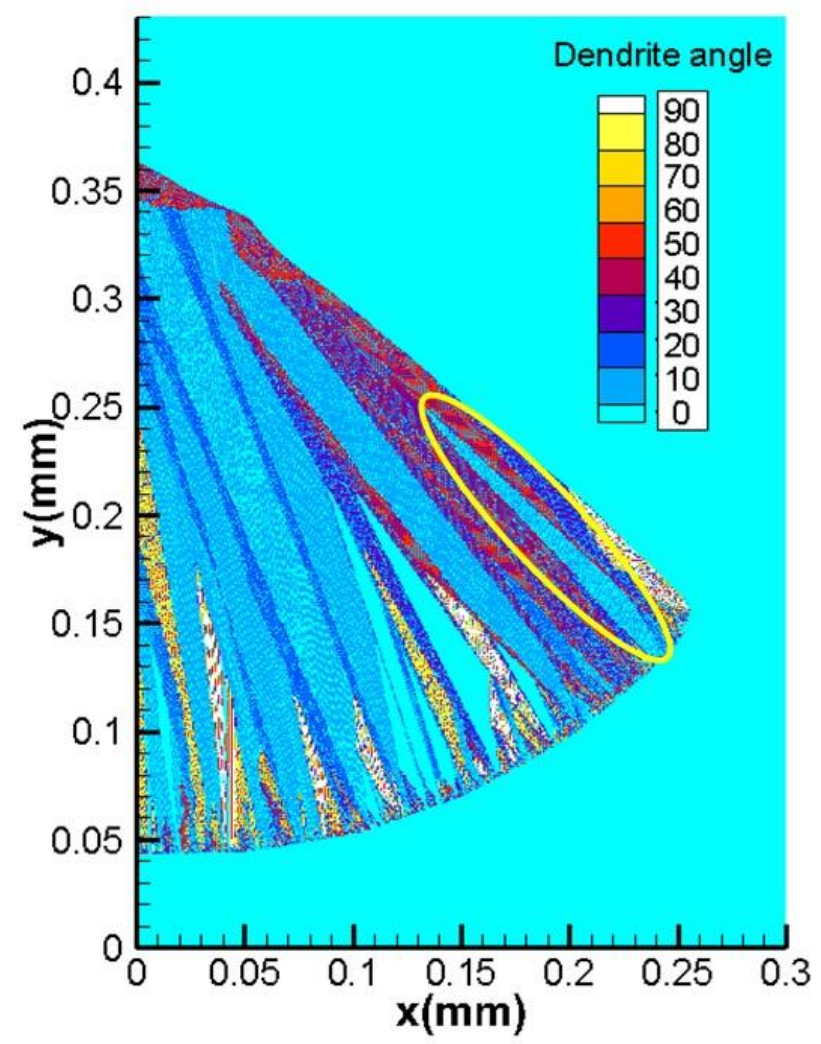

Figure 11: Solidification microstructure for the first track (Simulation 1) showing the angle of each dendrite between $0^{\circ}$ and $90^{\circ}$.

It is noted that all simulations from the CA-PF model are 2D. True grain growth is indeed a 3D phenomenon and a 3D simulation will always be superior to a $2 \mathrm{D}$ simulation without regard to computational cost. It is well known that the computational cost of a 3D simulation is usually 
several orders of magnitudes higher than a 2D simulation. Simulations performed in 2D have provided valid and useful data for decades and cannot be overlooked in their usefulness. However, one must be careful in choosing how to perform a 2D simulation of a 3D process [40].

Generally, in solidification conditions during welding or additive manufacturing, dendrites will grow toward the heat source. If the solidification speed of the grains is similar or slower than the heat source's travel speed, the grains will appear equiaxed in a cross-section perpendicular to the heat source's travel direction when in fact the grains are columnar in their growth direction. This will result in a misleading and inaccurate microstructure. However, if the grains' solidification speed is much faster than the heat source's travel speed (as is the case in the conditions in this work), the grains will grow quickly toward the center of the weld pool, resulting in accurate columnar grains as viewed in a cross-section perpendicular to the heat source's travel direction. This phenomenon is clearly explained by Tan et al. [26].

\subsection{Multi-track, multi-layer results}

After the first track is finished, the resulting microstructure (top left image of Figure 12) is used as the initial microstructure of the second track, Simulation 2. When the temperature is above the melting temperature, the solidified material in the corresponding region will be assigned as the liquid. Then as the temperature in Simulation 2 drops, dendrites again begin to form along the bottom of the molten pool. Once solidification of the second track is complete, the resulting microstructure (top right image of Figure 12) is used as the initial microstructure of the third track (Simulation 3), and the third track's final microstructure (bottom left image of Figure 12) is used as the initial microstructure of the fourth track (Simulation 4). The final 
predicted microstructure of the multi-track, multi-layer laser direct deposition simulation is shown in the bottom right image of Figure 12.

The final predicted microstructure, after all four simulations, should match the microstructure of the multi-layer, multi-track experimental microstructure shown in Figure 13 through Figure 15. Figure 13 is a microscope image of a cross-section of a two-layer multi-track LDD sample workpiece. The substrate and both layers are clearly shown. The box in Figure 13 represents the area of an SEM image shown in Figure 14.

Melt boundary lines were added to Figure 14 to indicate the melt boundaries of each laser track. The box "Detail A" represents the area of the zoomed-in SEM image at the bottom of Figure 15. Shown at 750x zoom, the SEM image in Figure 15 shows the dendritic details of the LDD microstructure as well as the melt boundaries between the tracks. The direction of dendrite growth is clear along the melt boundaries. This actual microstructure is compared with the top image in Figure 15, a zoomed-in image of the final predicted microstructure after all four CA-PF simulations (Detail B of Figure 12).

In comparing these two images, it is clear that the locations and curves of the molten pool boundaries agree, as do the average size and orientations of the dendrite arms near the molten pool boundaries. The arrows in Figure 15 assist in illustrating the agreement of directional growth between the predicted and experimental dendrites. The measured primary dendrite arm spacing for both the predicted and experimental dendrites agree well at around $2 \mu \mathrm{m}$. The CA-PF model accurately predicts the directional dendrite growth during LDD via multi-track and multilayer solidification simulations. 


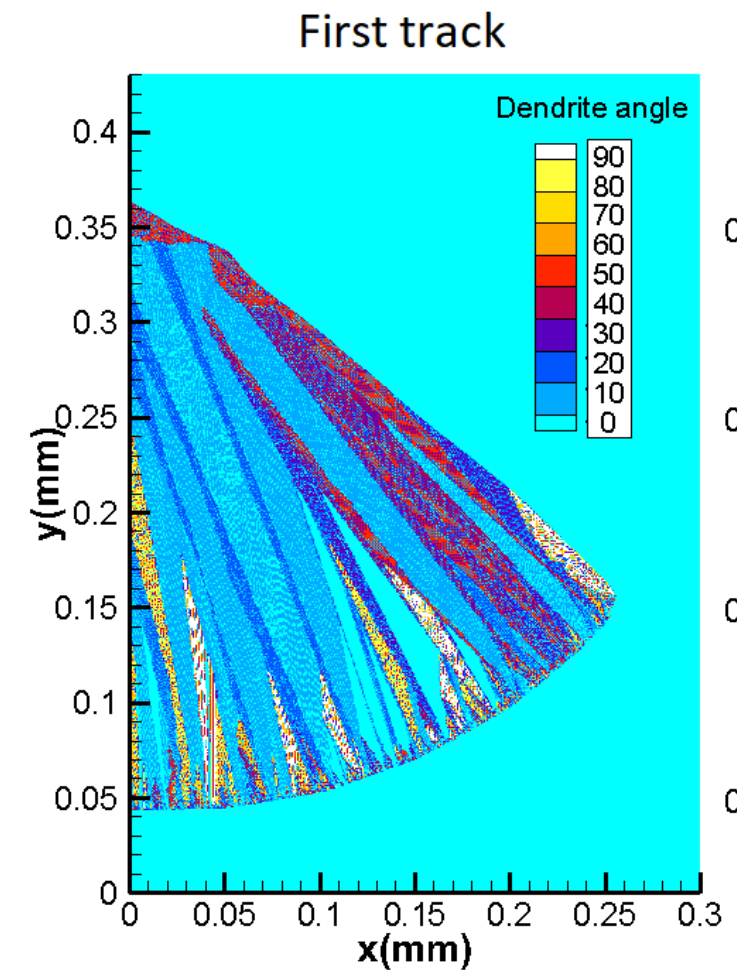

Third track

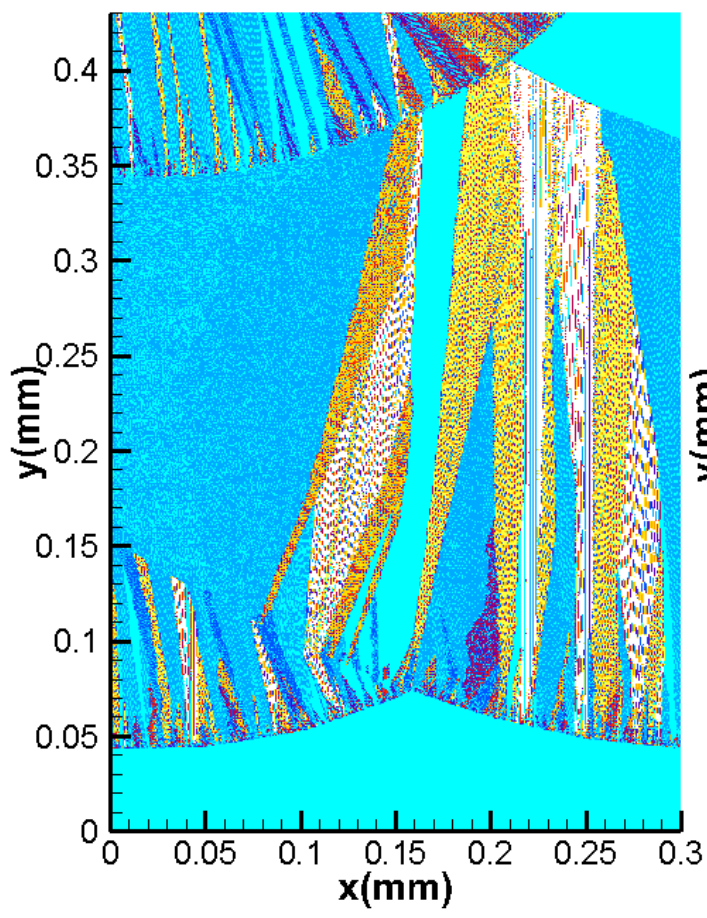

Second track

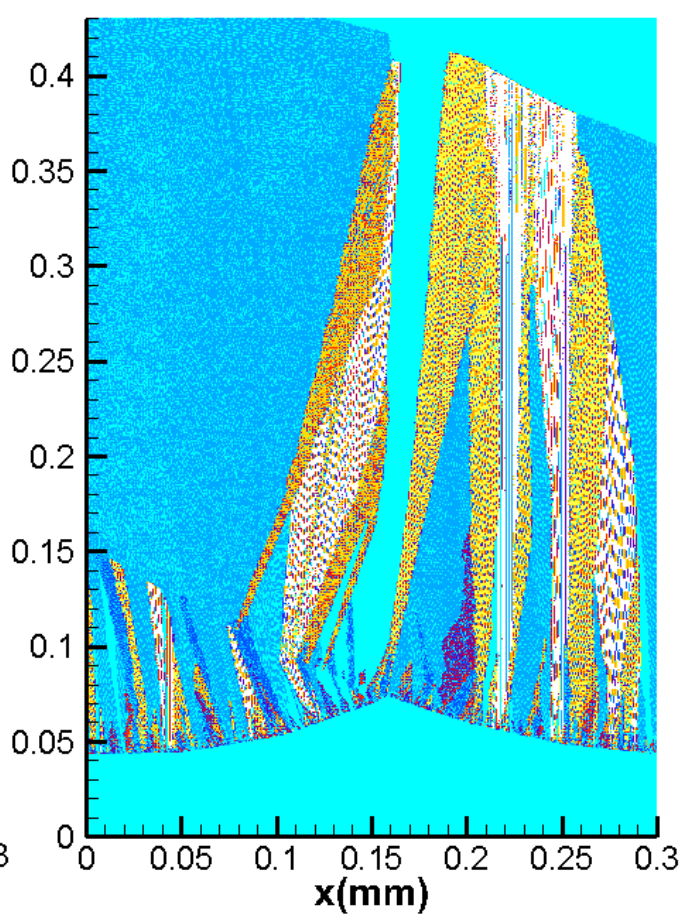

Fourth track

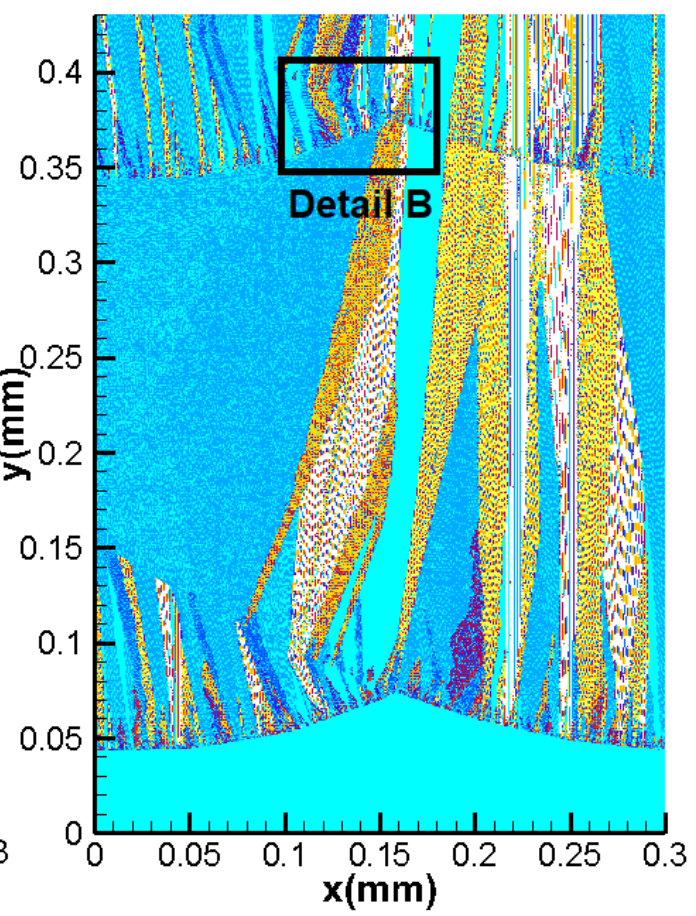

Figure 12: Predicted solidification microstructures for Simulations 1 through 4 showing the angle of each dendrite between $0^{\circ}$ and $90^{\circ}$. 


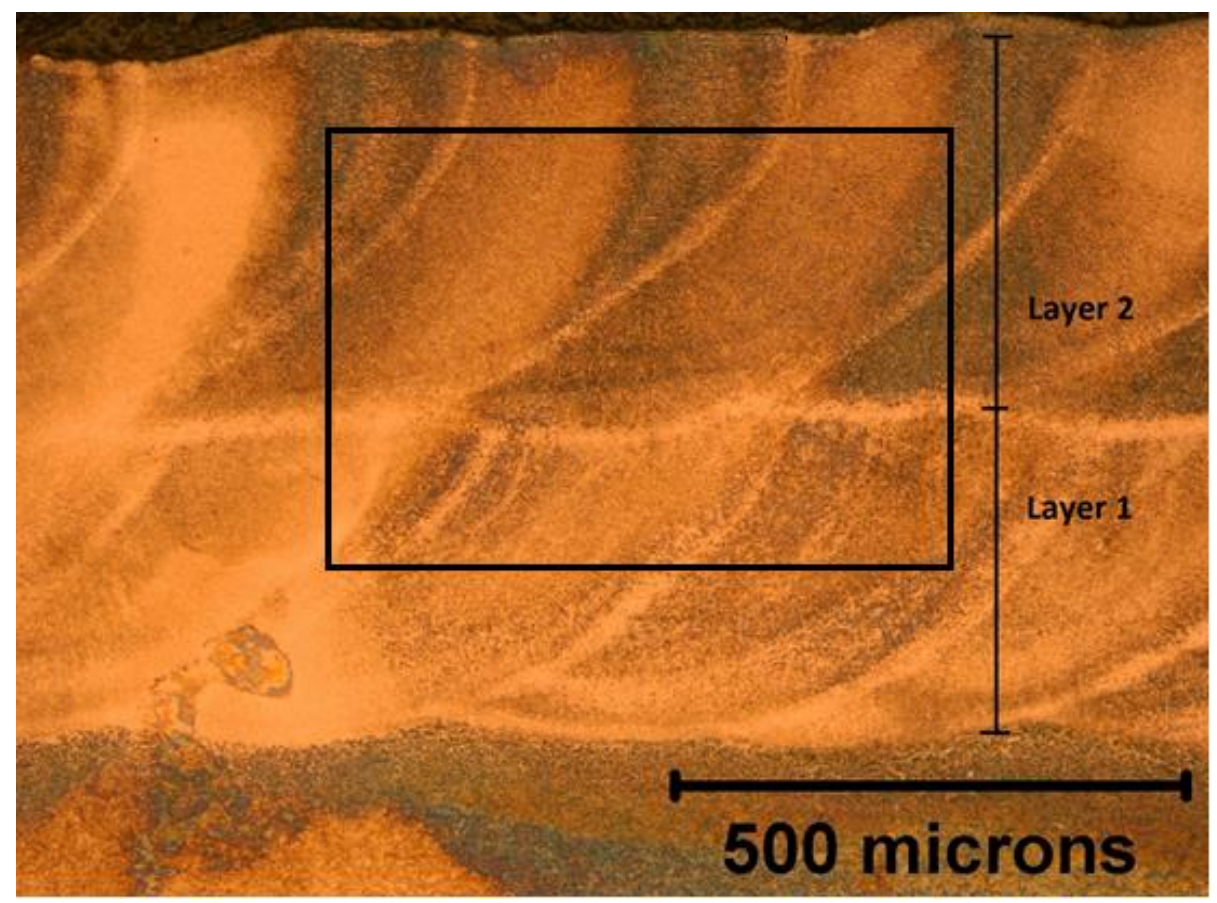

Figure 13: Microstructure from 2-layer experimental results. The region for Figure 14 is shown as a box.

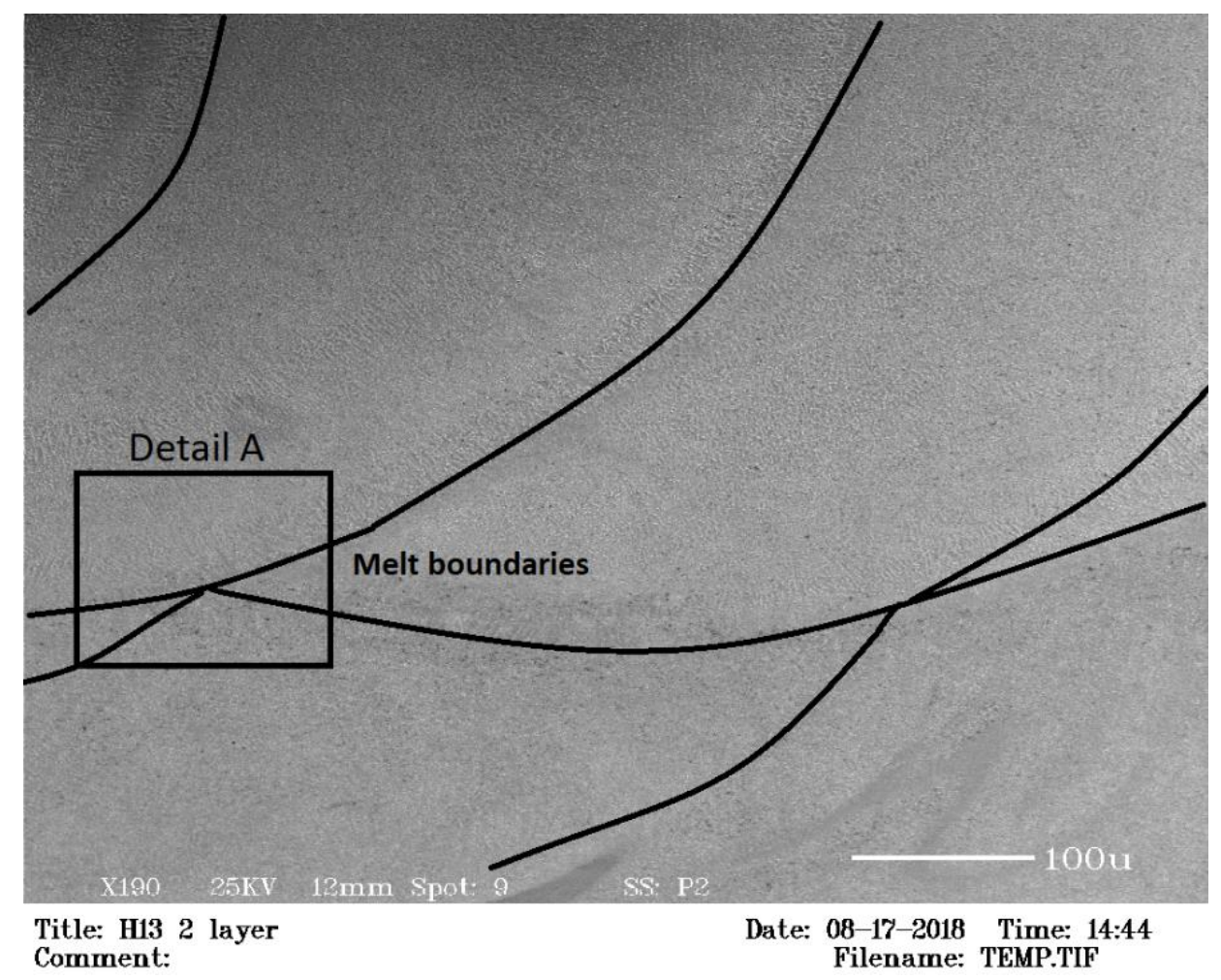

Figure 14: Melt boundaries are shown graphically. Detail region A is shown in Figure 15. 

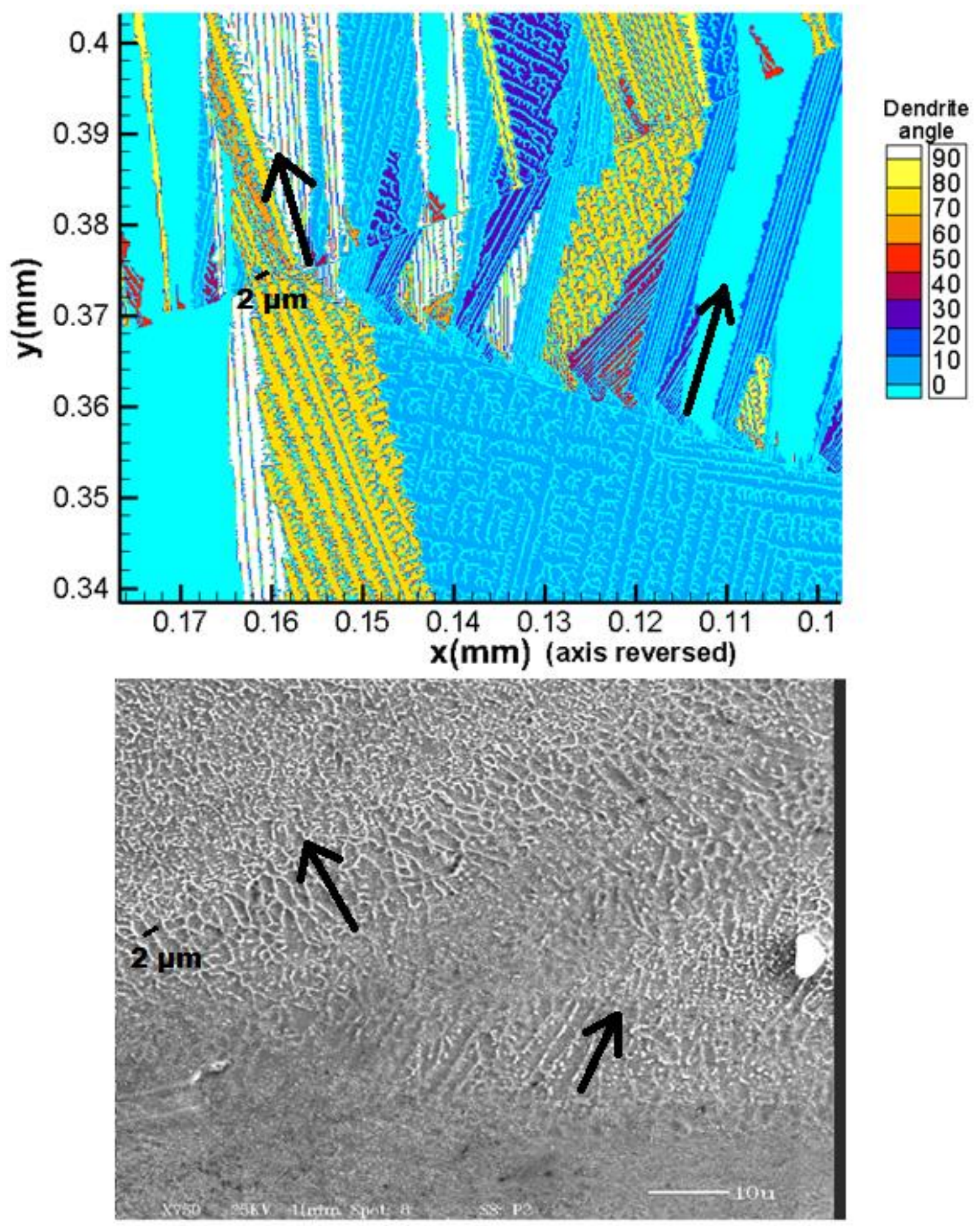

Titler Hus

Date: 09-05-2018 Time: 13:16

Comment: 2-layer

Filename: TEMP.TIF

Figure 15: Detail A (bottom) from Figure 14 compared with Detail B (top) from Figure 12. 


\subsection{Solid phase transformation results}

In addition to predicting dendrite growth during solidification, the CA-PF model has been expanded to include solid phase transformation prediction for hypoeutectoid steels. As noted above, austenite is the solidified phase, but H13 steel can undergo dramatic phase transformations during the repeated cooling and reheating cycles, which are typical in AM. Austenite is not stable at room temperature and the newly solidified material will quickly transform into other phases before the material reaches room temperature. Typical to LDD, quickly cooling austenite will transform to martensite, a body-centered tetragonal phase that has a very strong influence on the material hardness, strength, and distortion. Additionally, previously formed martensite is easily tempered by the heat of neighboring tracks in multi-track, multi-layer situations, resulting in additional phase transformation.

The post-cooling results of the solid phase transformation model for all four tracks are shown in Figure 16 in terms of the martensite phase fraction. For the first track, it is clear that the solidified and cooled material is nearly $100 \%$ martensite. This is expected since the entire molten pool solidifies as austenite and transforms to martensite due to the rapid cooling. The second track, as expected, also consists of nearly 100\% martensite. Even though not the entire region of the second track undergoes melting from the heat of its neighboring track, it does reach a temperature higher than the austenization temperature, thereby transforming every phase (along with newly solidified material) to austenite and then to martensite upon cooling. 

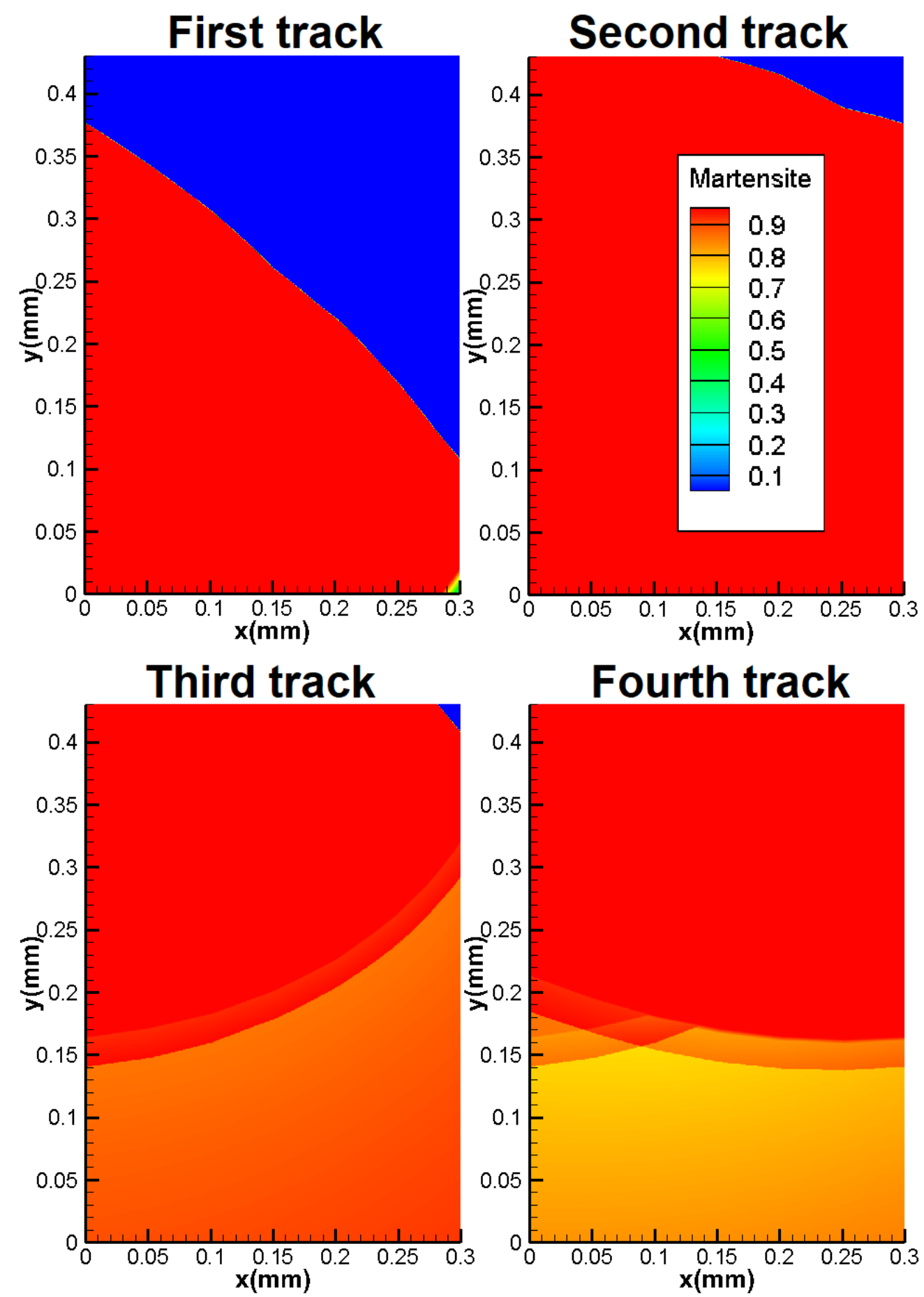

Figure 16: Predicted martensite phase fraction of each track after each simulation. 
A region within the third track undergoes a heating cycle from its upper neighbor, where the peak temperature is not high enough to cause austenization but is high enough to temper the existing martensite, as can be seen in the lower half of the third track image of Figure 16 where the phase fraction of martensite has dropped below 90\%. Additionally, the heat from a more distant neighboring track further tempers the martensite in the fourth track's region, resulting in an even lower phase fraction of martensite below $80 \%$.

According to the model, the tempered martensite forms three phases: ferrite, $\epsilon$-carbide, and cementite. The phase fraction of cementite is shown in Figure 17 where it can be seen that the degree of tempering increases between tracks three and four.
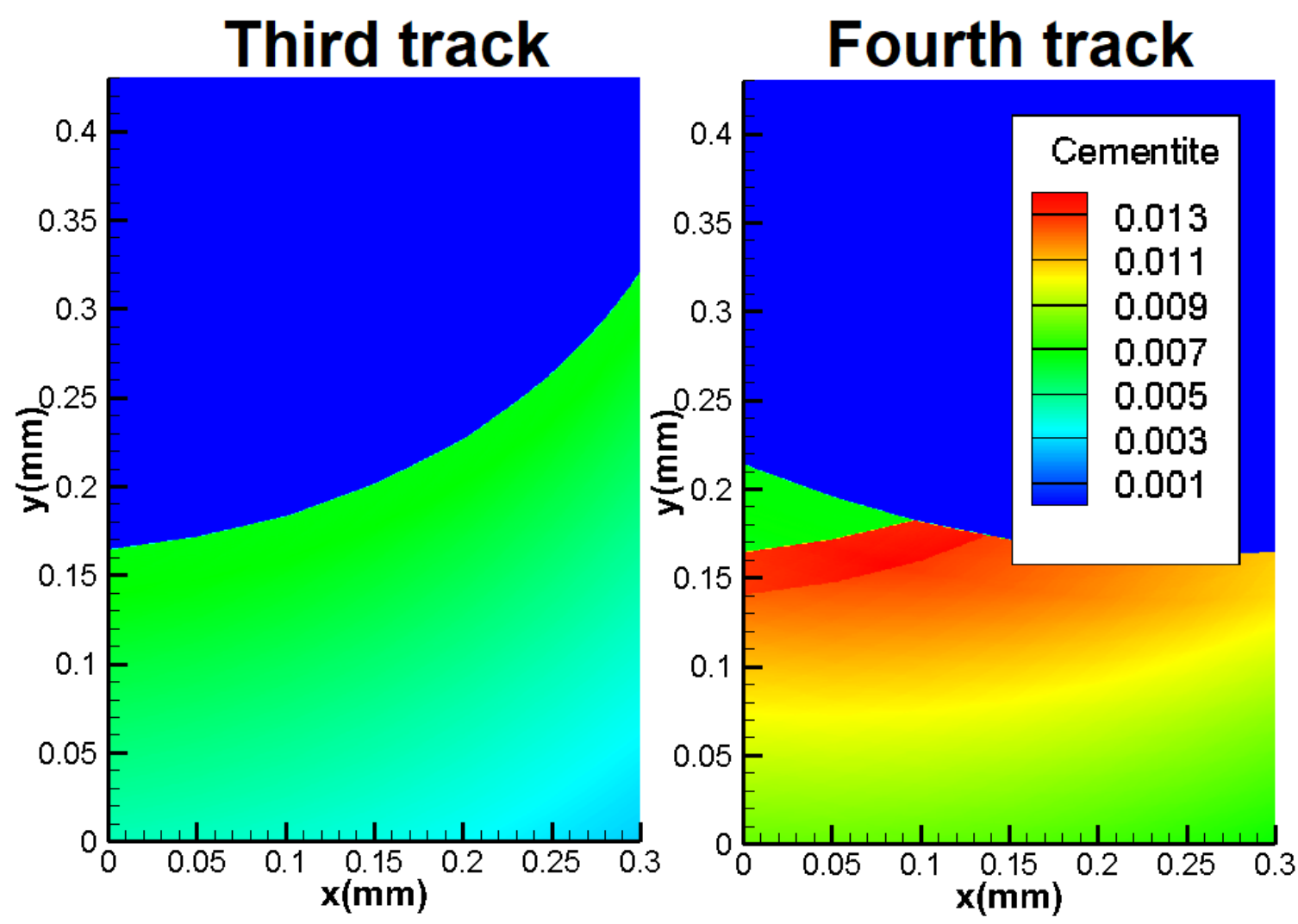

Figure 17: Predicted cementite phase fraction after tracks 3 and 4. 
To validate the solid phase transformation model, the hardness field was calculated for the domain shown in Figure 16 and Figure 17 according to Eq. (13) and compared to the experimental sample's measured hardness. Using a Vickers indenter, the hardness in the region of the sample shown in Figure 13 was tested across a $12 \times 10$ grid where each indentation was spaced $0.075 \mathrm{~mm}$ across a $0.900 \times 0.750$ region under $200 \mathrm{~g}$ load for 13 seconds, as shown in Figure 18. The measured hardness field data is shown in Figure 19 while the predicted hardness field data and the measured hardness field data are compared in Figure 20. Note that Detail C represents the same region in Figure 18, Figure 19, and Figure 20.

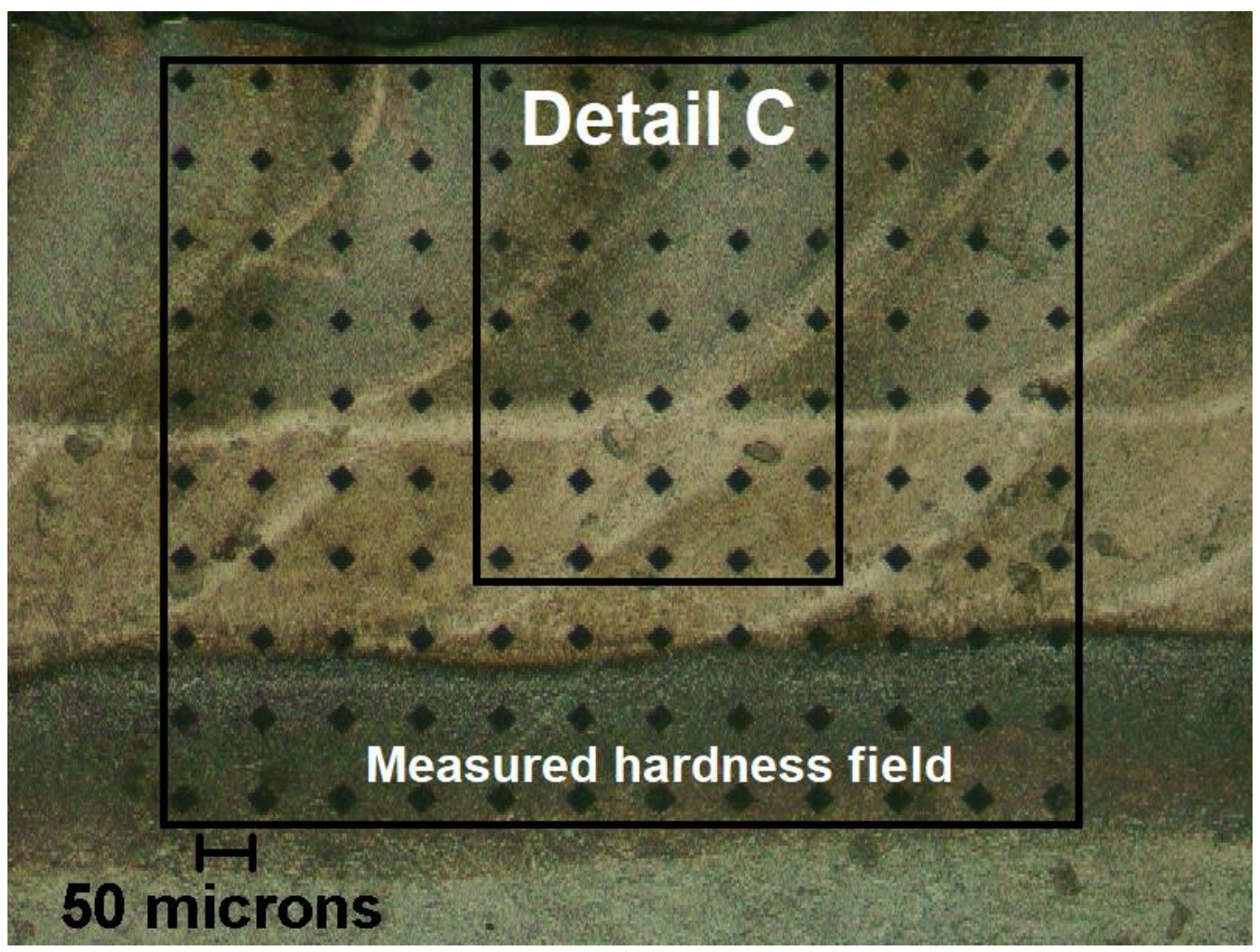

Figure 18: Vickers hardness indentation field (75 $\mu \mathrm{m}$ spacing). 


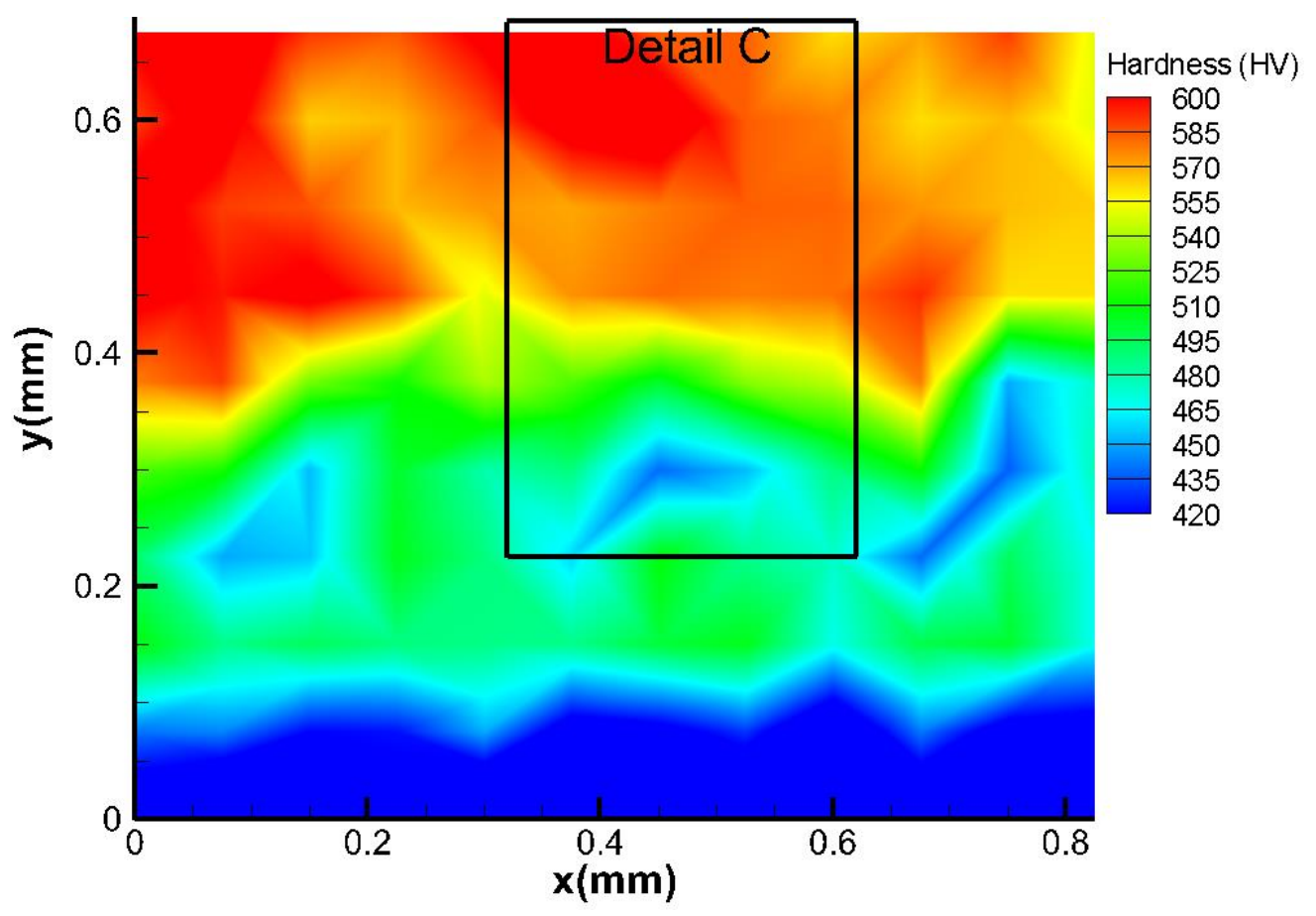

Figure 19: Measured hardness field (Vickers) corresponding to the region indicated in Figure 18.
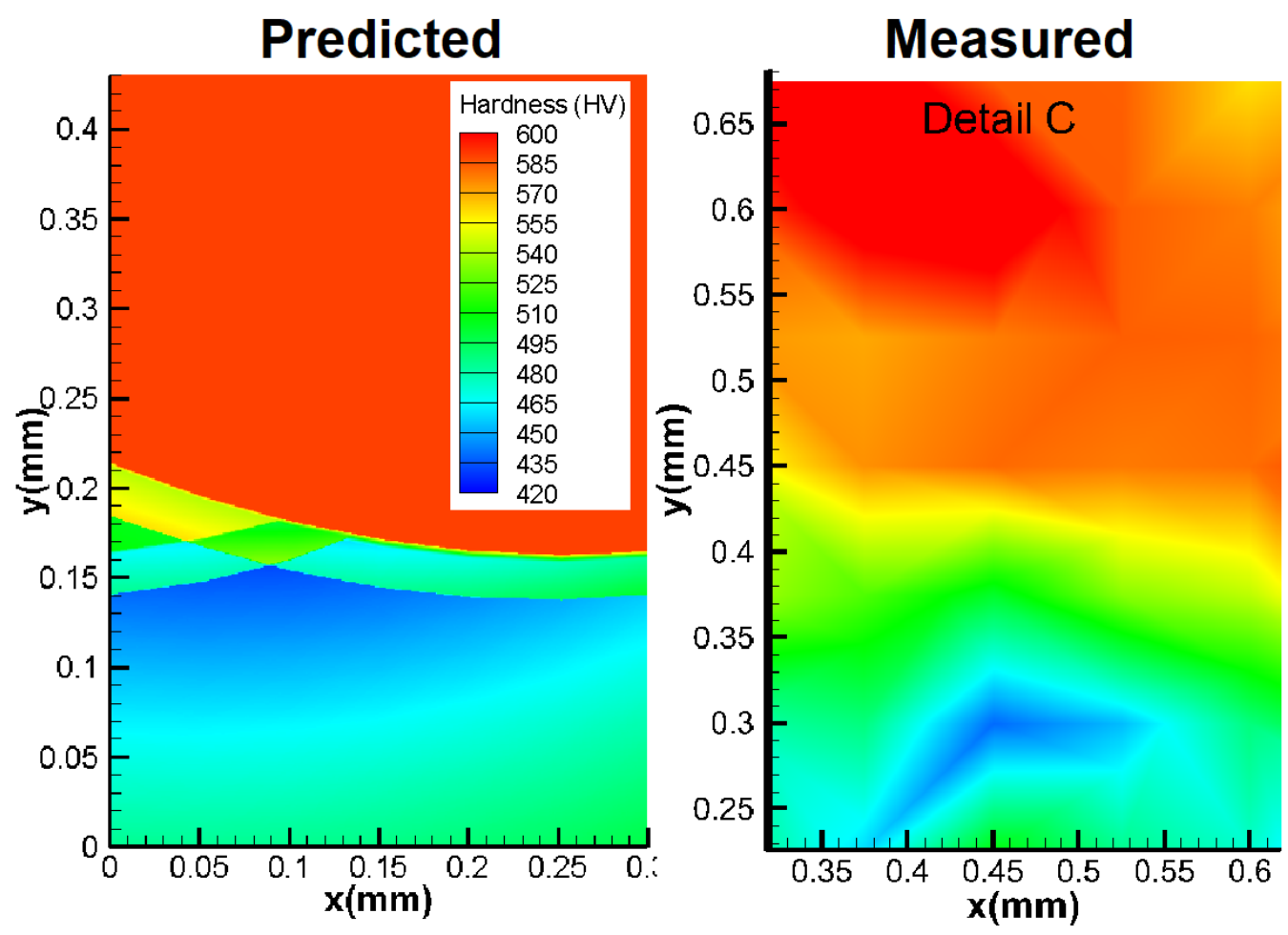

Figure 20: Predicted (left) VS measured (right) hardness fields. 
From the measured hardness field data in Figure 19, it is shown that the top layer of deposited material is rather hard, ranging between $570 \mathrm{HV}$ and $600 \mathrm{HV}$, which matches well with the predicted value of $589 \mathrm{HV}$. This corresponds to published data on typical H13 working hardness of 52-54 HRC [67]. Due to tempering from the top layer, the lower layer is softer, ranging between $550 \mathrm{HV}$ and $430 \mathrm{HV}$. Additionally, it can be seen from the measured hardness field in Figure 19 that the hardness field within the lower layer is horizontally periodic. Between $0.20 \mathrm{~mm}$ and $0.35 \mathrm{~mm}$ along the $\mathrm{y}$-axis, there are three softer regions spaced along the $\mathrm{x}$-axis at $0.15 \mathrm{~mm}, 0.45 \mathrm{~mm}$, and $0.70 \mathrm{~mm}$ where the maximum amount of tempering occurs from each top-layer track. The measured and predicted hardness in these soft spots match well at around $435 \mathrm{HV}$. Overall, the predicted hardness data matches well with measured hardness data, as can be seen from Figure 20, validating the phase data shown in Figure 16 and Figure 17.

\section{Conclusions}

The CA-PF model was used to simulate a multi-track and multi-layer LDD process. Using the CALPHAD method, the material, H13 tool steel was modeled as a ternary alloy consisting of Fe, 5.0 wt.\% Cr and 1.5 wt.\% Mo. The simulated deposition of multiple tracks and layers showed that the dendrite growth direction and scale across an entire weld pool $(430 \mu \mathrm{m} \times 300$ $\mu \mathrm{m})$ matched very well with experimental results. In addition to microstructure simulation, the model also predicted that during the deposition of a single track, the resultant phase is nearly all martensite due to the rapid cooling typical of laser-based additive processes. However, after multiple neighboring deposition tracks caused high- and low-level heating cycles to affect the target track, the previously formed martensite was considerably tempered to softer phases 
resulting in a reduction down to $80 \%$ martensite phase fraction and a reduction in hardness of $150 \mathrm{HV}$.

\section{Statements \& Declarations}

\section{Funding}

The authors declare that no funds, grants, or other support were received during the preparation of this manuscript.

\section{Competing Interests}

The authors have no relevant financial or non-financial interests to disclose.

\section{Author Contributions}

All authors contributed to the study conception and design. Material preparation, data collection and analysis were performed by Neil Bailey and Yung Shin. The first draft of the manuscript was written by Neil Bailey and all authors commented on previous versions of the manuscript. All authors read and approved the final manuscript.

\section{References}

[1] S. Wen and Y. C. Shin, "Modeling of transport phenomena during the coaxial laser direct deposition process," J. Appl. Phys., vol. 108, no. 4, 2010.

[2] S. Wen and Y. C. Shin, "Modeling of the off-axis high power diode laser cladding process," J. Heat Transfer, vol. 133, no. 3, p. 31007, 2011.

[3] D. Cormier, O. Harrysson, and H. West, "Characterization of H13 steel produced via electron beam melting," Rapid Prototyp. J., vol. 10, no. 1, pp. 35-41, 2004.

[4] M. Mazur, M. Leary, M. McMillan, J. Elambasseril, and M. Brandt, "SLM additive 
manufacture of H13 tool steel with conformal cooling and structural lattices," Rapid Prototyp. J., vol. 22, no. 3, pp. 504-518, 2016.

[5] M. Mazur, P. Brincat, M. Leary, and M. Brandt, "Numerical and experimental evaluation of a conformally cooled H13 steel injection mould manufactured with selective laser melting," Int. J. Adv. Manuf. Technol., vol. 93, no. 1-4, pp. 881-900, 2017.

[6] W. Tan, N. S. Bailey, and Y. C. Shin, "Investigation of keyhole plume and molten pool based on a three-dimensional dynamic model with sharp interface formulation," J. Phys. D. Appl. Phys., vol. 46, no. 5, p. 55501, 2013.

[7] W. Tan, S. Wen, N. Bailey, and Y. C. Shin, "Multiscale Modeling of Transport Phenomena and Dendritic Growth in Laser Cladding Processes," Metall. Mater. Trans. B, vol. 42, no. 6, pp. 1306-1318, 2011.

[8] S. Wen and Y. C. Shin, "Comprehensive predictive modeling and parametric analysis of multitrack direct laser deposition processes Comprehensive predictive modeling and parametric analysis of multitrack direct laser deposition processes," ASM Int., vol. 022003, no. 2011, pp. 1-7, 2013.

[9] N. S. Bailey, C. Katinas, and Y. C. Shin, "Laser direct deposition of AISI H13 tool steel powder with numerical modeling of solid phase transformation, hardness, and residual stresses," J. Mater. Process. Technol., vol. 247, pp. 223-233, 2017.

[10] M. C. Flemings, “Solidification processing," Metall. Trans., vol. 5, no. 10, pp. 21212134, 1974.

[11] W. Kurz and D. Fisher, Fundamentals of solidification, fourth ed. Enfield, NH: Enfield Publishing \& Distribution Company, 1998.

[12] D. M. Stefanescu, Science and engineering of casting solidification, second ed. Springer, 2010.

[13] M. F. Zhu and C. P. Hong, "A Three Dimensional Modified Cellular Automaton Model for the Prediction of Solidification Microstructures.," ISIJ Int., vol. 42, no. 5, pp. 520-526, 2002.

[14] W. Kurz, B. Giovanola, and R. Trivedi, "Theory of microstructural development during rapid solidification," Acta Metall., vol. 34, no. 5, pp. 823-830, 1986.

[15] L. Beltran-Sanchez and D. M. Stefanescu, "Growth of solutal dendrites: a cellular automaton model and its quantitative capabilities," Metall. Mater. Trans. A, vol. 34, no. 2, pp. 367-382, 2003.

[16] V. Pavlyk and U. Dilthey, "Simulation of weld solidification microstructure and its coupling to the macroscopic heat and fluid flow modelling," Model. Simul. Mater. Sci. Eng., vol. 12, no. 1, p. S33, 2003.

[17] W. Wang, P. D. Lee, and M. Mclean, "A model of solidification microstructures in nickelbased superalloys: predicting primary dendrite spacing selection," Acta Mater., vol. 51, no. 10, pp. 2971-2987, 2003. 
[18] M. J. M. Krane, D. R. Johnson, and S. Raghavan, "The development of a cellular automaton-finite volume model for dendritic growth," Appl. Math. Model., vol. 33, no. 5, pp. 2234-2247, 2009.

[19] M. Zhu, S. Pan, D. Sun, and H. Zhao, "Numerical simulation of microstructure evolution during alloy solidification by using cellular automaton method," ISIJ Int., vol. 50, no. 12, pp. 1851-1858, 2010.

[20] H. B. Dong and P. D. Lee, "Simulation of the columnar-to-equiaxed transition in directionally solidified Al--Cu alloys," Acta Mater., vol. 53, no. 3, pp. 659-668, 2005.

[21] M. F. Zhu and D. M. Stefanescu, "Virtual front tracking model for the quantitative modeling of dendritic growth in solidification of alloys," Acta Mater., vol. 55, no. 5, pp. 1741-1755, 2007.

[22] S. Pan and M. Zhu, "A three-dimensional sharp interface model for the quantitative simulation of solutal dendritic growth," Acta Mater., vol. 58, no. 1, pp. 340-352, 2010.

[23] S. C. Michelic, J. M. Thuswaldner, and C. Bernhard, "Polydimensional modelling of dendritic growth and microsegregation in multicomponent alloys," Acta Mater., vol. 58, no. 7, pp. 2738-2751, 2010.

[24] Q. Li, Y. Wang, H. W. Zhang, S. S. Xie, and G. J. Huang, "Numerical simulation of microstructure and solutal microsegregation formation of ternary alloys during solidification process," Ironmak. Steelmak., 2013.

[25] R. Chen, Q. Xu, and B. Liu, "Cellular automaton simulation of three-dimensional dendrite growth in Al-7Si-Mg ternary aluminum alloys," Comput. Mater. Sci., vol. 105, pp. 90$100,2015$.

[26] W. Tan and Y. C. Shin, "Multi-scale modeling of solidification and microstructure development in laser keyhole welding process for austenitic stainless steel," Comput. Mater. Sci., vol. 98, pp. 446-458, 2015.

[27] C. Gu, C. D. Ridgeway, and A. A. Luo, "Examination of dendritic growth during solidification of ternary alloys via a novel quantitative 3D cellular automaton model," Metall. Mater. Trans. B, vol. 50, no. 1, pp. 123-135, 2019.

[28] X. Ao, H. Xia, J. Liu, and Q. He, "Simulations of microstructure coupling with moving molten pool by selective laser melting using a cellular automaton," Mater. Des., vol. 185, p. 108230, 2020.

[29] M. Ode, S. G. Kim, and T. Suzuki, "Recent advances in the phase-field model for solidification," ISIJ Int., vol. 41, no. 10, pp. 1076-1082, 2001.

[30] W. J. Boettinger, J. A. Warren, C. Beckermann, and A. Karma, "Phase-field simulation of solidification," Mater. Res., vol. 32, no. 1, p. 163, 2002.

[31] L.-Q. Chen, "Phase-field models for microstructure evolution," Annu. Rev. Mater. Res., vol. 32, no. 1, pp. 113-140, 2002.

[32] L. Gránásy, T. Pusztai, and J. A. Warren, "Modelling polycrystalline solidification using 
phase field theory," J. Phys. Condens. Matter, vol. 16, no. 41, p. R1205, 2004.

[33] T. Takaki, M. Ohno, T. Shimokawabe, and T. Aoki, "Two-dimensional phase-field simulations of dendrite competitive growth during the directional solidification of a binary alloy bicrystal," Acta Mater., vol. 81, pp. 272-283, 2014.

[34] U. Grafe, B. Böttger, J. Tiaden, and S. G. Fries, "Coupling of multicomponent thermodynamic databases to a phase field model: application to solidification and solid state transformations of superalloys," Scr. Mater., vol. 42, no. 12, pp. 1179-1186, 2000.

[35] M. Ode, J. S. Lee, S. G. Kim, W. T. Kim, and T. Suzuki, "Phase-field Model for Solidification of Ternary Alloys.," ISIJ Int., vol. 40, no. 9, pp. 870-876, 2000.

[36] P.-R. Cha, D.-H. Yeon, and J.-K. Yoon, "A phase field model for isothermal solidification of multicomponent alloys," Acta Mater., vol. 49, no. 16, pp. 3295-3307, 2001.

[37] H. Kobayashi, M. Ode, S. G. Kim, W. T. Kim, and T. Suzuki, "Phase-field model for solidification of ternary alloys coupled with thermodynamic database," Scr. Mater., vol. 48, no. 6, pp. 689-694, 2003.

[38] R. S. Qin, E. R. Wallach, and R. C. Thomson, "A phase-field model for the solidification of multicomponent and multiphase alloys," J. Cryst. Growth, vol. 279, no. 1, pp. 163-169, 2005 .

[39] L. Zhang, E. V. Danilova, I. Steinbach, D. Medvedev, and P. K. Galenko, "Diffuseinterface modeling of solute trapping in rapid solidification: Predictions of the hyperbolic phase-field model and parabolic model with finite interface dissipation," Acta Mater., vol. 61, no. 11, pp. 4155-4168, 2013.

[40] N. S. Bailey, K.-M. Hong, and Y. C. Shin, "Comparative assessment of dendrite growth and microstructure predictions during laser welding of $\mathrm{Al} 6061$ via $2 \mathrm{D}$ and $3 \mathrm{D}$ phase field models," Comput. Mater. Sci., vol. 172, p. 109291, 2020.

[41] T. Suzuki, M. Ode, S. G. Kim, and W. T. Kim, "Phase-field model of dendritic growth," J. Cryst. Growth, vol. 237, pp. 125-131, 2002.

[42] S. G. Kim, W. T. Kim, and T. Suzuki, "Phase-field model for binary alloys," Phys. Rev. e, vol. 60, no. 6, p. 7186, 1999.

[43] P.-R. Cha, D.-H. Yeon, and J.-K. Yoon, "Phase-field model for multicomponent alloy solidification," J. Cryst. Growth, vol. 274, no. 1, pp. 281-293, 2005.

[44] M. Berghoff and B. Nestler, "Phase field crystal modeling of ternary solidification microstructures," Comput. Condens. Matter, vol. 4, pp. 46-58, 2015.

[45] B. Böttger, J. Eiken, and I. Steinbach, "Phase field simulation of equiaxed solidification in technical alloys," Acta Mater., vol. 54, no. 10, pp. 2697-2704, 2006.

[46] J. Eiken, "Phase-field simulation of microstructure formation in technical magnesium alloys," Int. J. Mater. Res., vol. 101, no. 4, pp. 503-509, 2010.

[47] N. Provatas, N. Goldenfeld, and J. Dantzig, "Efficient computation of dendritic 
microstructures using adaptive mesh refinement," Phys. Rev. Lett., vol. 80, no. 15, p. 3308, 1998.

[48] N. Provatas, M. Greenwood, B. Athreya, N. Goldenfeld, and J. Dantzig, "Multiscale modeling of solidification: phase-field methods to adaptive mesh refinement," Int. J. Mod. Phys. B, vol. 19, no. 31, pp. 4525-4565, 2005.

[49] W. M. Feng, P. Yu, S. Y. Hu, Z.-K. Liu, Q. Du, and L.-Q. Chen, "Spectral implementation of an adaptive moving mesh method for phase-field equations," J. Comput. Phys., vol. 220, no. 1, pp. 498-510, 2006.

[50] W. Tan, N. S. Bailey, and Y. C. Shin, "A novel integrated model combining Cellular Automata and Phase Field methods for microstructure evolution during solidification of multi-component and multi-phase alloys," Comput. Mater. Sci., vol. 50, no. 9, pp. 25732585, 2011.

[51] N. S. Bailey, W. Tan, and Y. C. Shin, "Predictive modeling and experimental results for residual stresses in laser hardening of AISI 4140 steel by a high power diode laser," Surf. Coatings Technol., vol. 203, no. 14, pp. 2003-2012, 2009.

[52] C. Katinas, W. Shang, Y. C. Shin, and J. Chen, "Modeling Particle Spray and Capture Efficiency for Direct Laser Deposition Using a Four Nozzle Powder Injection System," J. Manuf. Sci. Eng., vol. 140, no. 4, p. 41014, 2018.

[53] S. Osher and J. A. Sethian, "Fronts propagating with curvature-dependent speed: algorithms based on Hamilton-Jacobi formulations," J. Comput. Phys., vol. 79, no. 1, pp. 12-49, 1988.

[54] W. Wang, P.D. Lee, M. McLean, "A Model of Solidification Microstructures in NickelBased Superalloys: Predicting Primary Dendrite Spacing Selection". Acta Materialia, 51, 2971-2987, 2003.

[55] S. Raghavan, "A Numerical Model For Dendritic Growth In Binary Alloys," Purdue University, 2005.

[56] M. A. Martorano, M. A. Fortes, and A. F. Padilha, "A numerical method for curvature driven boundary migration," Model. Simul. Mater. Sci. Eng., vol. 14, no. 1, p. 83, 2006.

[57] R. Zhang, T. Jing, W. Jie, and B. Liu, "Phase-field simulation of solidification in multicomponent alloys coupled with thermodynamic and diffusion mobility databases," Acta Mater., vol. 54, no. 8, pp. 2235-2239, 2006.

[58] S. G. Kim, "A phase-field model with antitrapping current for multicomponent alloys with arbitrary thermodynamic properties," Acta Mater., vol. 55, no. 13, pp. 4391-4399, 2007.

[59] S. Skvarenina and Y. C. Shin, "Predictive modeling and experimental results for laser hardening of AISI 1536 steel with complex geometric features by a high power diode laser," Surf. Coatings Technol., vol. 201, no. 6, pp. 2256-2269, 2006.

[60] M. F. Ashby and K. E. Easterling, "The transformation hardening of steel surfaces by laser beams: I. Hypo-eutectoid steels," Acta Metall., vol. 32, no. 11, pp. 1935-1948, 1984. 
[61] R. S. Lakhkar, Y. C. Shin, and M. J. M. Krane, "Predictive modeling of multi-track laser hardening of AISI 4140 steel," Mater. Sci. Eng. A, vol. 480, no. 1, pp. 209-217, 2008.

[62] W. D. Callister and D. G. Rethwisch, Materials science and engineering: an introduction, vol. 7. Wiley New York, 2007.

[63] S.-H. Kang and Y.-T. Im, "Three-dimensional finite-element analysis of the quenching process of plain-carbon steel with phase transformation," Metall. Mater. Trans. A, vol. 36, no. 9, pp. 2315-2325, 2005.

[64] P. R. Woodard, S. Chandrasekar, and H. T. Y. Yang, "Analysis of temperature and microstructure in the quenching of steel cylinders," Metall. Mater. Trans. B, vol. 30, no. 4, pp. 815-822, 1999.

[65] R. Patwa and Y. C. Shin, "Predictive modeling of laser hardening of AISI5150H steels," Int. J. Mach. Tools Manuf., vol. 47, no. 2, pp. 307-320, 2007.

[66] J.-O. Andersson and N. Lange, "An experimental study and a thermodynamic evaluation of the Fe-Cr-Mo system," Metall. Trans. A, vol. 19, no. 6, pp. 1385-1394, 1988.

[67] J. C. Benedyk, "High Performance Alloys Database, H13." CINDAS LLC, West Lafayette, IN, 2008.

[68] N. S. Bailey, C. Katinas, and Y. C. Shin, "Laser direct deposition of AISI H13 tool steel powder with numerical modeling of solid phase transformation, hardness, and residual stresses," J. Mater. Process. Technol., vol. 247, 2017. 